\title{
Contribución de guerra y negociaciones: la política fiscal del virrey La Serna en Lima (1821)/
}

\author{
War Tax and Negotiations: the Fiscal Policy \\ of Viceroy La Serna in Lima (1821)
}

\author{
Dionisio de Haro Romero \\ ORCID iD: http://orcid.org/0000-0002-0440-4948 \\ Universidad Rey Juan Carlos \\ Alfredo Moreno Cebrián \\ ORCID iD: http://orcid.org/0000-0002-5170-7415 \\ Centro de Ciencias Humanas y Sociales, CSIC
}

El artículo analiza la recepción en el Perú del ideario fiscal de la Constitución de Cádiz por parte del gobierno político-militar del virrey La Serna. El trabajo pretende mostrar el caso que lo ejemplifica, la aprobación de una contribución extraordinaria de guerra, cuyo monto debía distribuirse, tras la elaboración de los correspondientes padrones, en función de la capacidad económica de los contribuyentes, y no en repartimientos sujetos a corporaciones y gremios. La falta de sintonía entre el Ayuntamiento constitucional y el virrey acabó por precipitar al fracaso las negociaciones y certificó la voluntad del gobierno en la búsqueda de nuevas bases sobre las que sostener el esfuerzo bélico.

Palabras clave: Trienio Liberal; Negociación; Cortes; Virreinato Perú; Política Fiscal; Historia Económica; Ayuntamientos Constitucionales; Lima.

The article analyzes the reception in Peru of the fiscal ideas reflected in the liberal Constitution of Cadiz by viceroy La Serna's political-military government. The essay aims to discuss the case in which this is exemplified: the production of the census of the city of Lima in order to introduce and apply an extraordinary war contribution, the amount of which was to be distributed proportionally to the economic capacity of the taxpayers, and not by means of distributions subject to corporations and guilds. The lack of agreement between the Constitutional City Council and the viceroy condemned the negotiations to failure and consolidated the government's decision to seek new resources with which to support the war effort.

KeYwords: Liberal Triennium; Negotiation; Cortes; Viceroyalty of Peru; Fiscal Policy; Economic History; Constitutional Local Governments; Lima.

Copyright: (C) 2018 CSIC. Este es un artículo de acceso abierto distribuido bajo los términos de la licencia de uso y distribución Creative Commons Reconocimiento 4.0 Internacional (CC BY 4.0). 


\section{Introducción}

La relación entre fiscalidad, configuración institucional y actores sociales se presenta como una de las perspectivas de investigación más idóneas para estudiar las dinámicas de poder en las formaciones políticas. De hecho, los mecanismos, el volumen y el destino de las finanzas públicas pueden ser tenidos como la expresión de acuerdos y equilibrios, tanto explícitos como implícitos, en los que se conjuga lo social, lo político, lo económico, e incluso lo cultural. ${ }^{1}$

En Perú, a partir de la guerra de la Independencia, política y fiscalidad conformaron un espacio común en el que acabaron por definirse los rasgos sustanciales de la que será la nueva acción del gobierno. Las autoridades realistas, asentadas sobre las bases renovadas que ofrece la Constitución de 1812, aspiraron a consolidar el dominio territorial y a cimentar el poder. La estructura fiscal, que trató de maximizar las premisas liberales, fue modificándose como resultado de la continua tensión entre el virrey y las élites locales en torno al gobierno económico de los territorios coloniales. El proceso de articulación fiscal, responsable de que diversos intereses fueran integrados en un determinado modelo de gestión, deambuló desde la acusada descentralización, en consonancia con un poder central ahogado por la guerra y la crisis y necesitado de la colaboración local para sostener un mínimo aliento fiscal, hasta la centralización, concebida en el anhelo de un mayor control político que acompañase a un incremento de los ingresos fiscales. De este modo, la definición del marco fiscal y la organización del sistema de distribución de fondos públicos permanecieron en continua revisión y sometidos a una disputada dinámica de negociación, con el objeto de armonizar intereses y conciliar tendencias no siempre recurrentes. Para el caso que nos ocupa, la «nerviosa» relación entre política y hacienda acabó desembocando en un profundo divorcio, que se concretará en la evacuación de Lima por parte del gobierno virreinal, buscando nuevas bases sobre las que sostener los esfuerzos bélicos.

1 Este artículo forma parte del proyecto de investigación «Cambios e innovaciones sociales: España y el Perú de la crisis del Imperio transoceánico al Estado liberal», dirigido por Alfredo Moreno Cebrián dentro del programa estatal de I+D+i «Retos de la Sociedad», financiado por el Ministerio de Economía y Competitividad de España (HAR 2015-67197-R). Asimismo, el presente trabajo se ha realizado al amparo del convenio específico de colaboración entre la Universidad Rey Juan Carlos y el CSIC (estancia de Dionisio de Haro Romero en el Instituto de Historia del CSIC durante el curso académico 2016-2017). Agradecemos a nuestros colegas Ascensión Martínez Riaza y Víctor Peralta sus siempre acertados comentarios y observaciones. Asimismo, queremos hacer un reconocimiento explícito al personal de los diferentes archivos consultados que, con su eficacia y amabilidad, facilitaron nuestra investigación. 
La recuperación de la Constitución de la Monarquía española en el Trienio Liberal (1820-1823) sigue planteando recurrentes interrogantes en cuanto a su influencia en los gobiernos virreinales de la América continental ${ }^{2}$ y para el caso del Perú el análisis se complica aun más con el controvertido suceso del Motín de Aznapuquio, en el que por vez primera un virrey, Joaquín de la Pezuela, es obligado a ceder el mando al militar de mayor rango, en este caso al teniente general José de la Serna e Hinojosa. ${ }^{3}$ Asimismo, la escasa disponibilidad de fuentes documentales históricas reduce la capacidad de análisis crítico en torno a la naturaleza del nuevo gabinete político-militar de este virrey, limitando extraordinariamente el estudio de lo que fue su futura acción de gobierno.

En este complejo escenario histórico, el presente trabajo centra su atención en las medidas de orden fiscal adoptadas por las nuevas autoridades durante el primer semestre del año 1821, desde la asunción del poder por La Serna, tras el pronunciamiento de Aznapuquio del 28 de enero, hasta la mañana del 7 de julio, cuando el ejército realista procedió a la evacuación de Lima. Central ha resultado la consulta de los registros de los documentos depositados en el Archivo General de la Nación y el de la Municipalidad de Lima que, con las debidas cautelas, se nos han revelado como fuentes fundamentales para llevar adelante una aproximación fiscal inédita, en la que se revelan sugerentes permeabilidades entre el espíritu liberal de la carta gaditana y las iniciativas hacendísticas que el nuevo gobierno virreinal, en sintonía con la Diputación provincial, adoptó sin dilación.

\section{La reforma fiscal gaditana}

España transitó, en los últimos años del siglo XVIII y en los primeros del siglo XIX, por el tortuoso camino del descuadre fiscal. Mientras los gastos anuales prácticamente se doblaron, los ingresos permanecieron tozudamente estancados. ${ }^{4} \mathrm{El}$ recurso al crédito y el apoyo que todavía supusieron para los fondos públicos los caudales de Indias, alargaron una agonía irresoluble hasta el estallido de la Guerra de la Independencia en España

2 Gil Novales, 1979. Lynch, 1989 [1976]. Martínez Torrón, 1992, 41-46. Jensen, 1996. Sánchez Andrés, 1997. Hamnett, 2000. Fisher, 2000. Rodríguez, 2005. Peralta, 2008. Sala i Vila, 2011. Landa Arroyo, 2012. Martínez Riaza, 2014. Para Ortemberg $(2009,98)$ la influencia gaditana traspasará los límites del Protectorado.

3 Puente Candamo, 1992. Fisher, 2006. Mark, 2007.

4 Fontana, 1980, 27-38. 
(1808-1814). Entonces, colapsada la estructura del Antiguo Régimen, la reforma de la hacienda se convirtió en una necesidad vital para el Estado español. La primera ola reformista aspiró a la revitalización de los ingresos, reorientando la naturaleza del aparato fiscal, y al replanteamiento de una base económica renovada y acorde con las exigencias de los nuevos tiempos. El liberalismo fiscal gaditano rescató de la experiencia ilustrada la «única contribución» y fijó especial atención en el ámbito local como espacio natural de la reforma. ${ }^{5}$

El 1 de abril de 1811 las Cortes generales y extraordinarias aprobaron el decreto «Nueva forma de la contribución extraordinaria de guerra», que rescatando parcialmente la fallida norma anterior de la Junta Central, de 12 de enero de 1810, gravaba a todos los ciudadanos en proporción a los réditos y productos líquidos de fincas, actividades comerciales y producción industrial. Asimismo, la cuota aplicable a cada contribuyente se estableció en tramos que abarcaron desde el 2,5\% al $75 \% .{ }^{6}$ Pero la falta del aparato estadístico necesario dejó el esfuerzo reformista en papel mojado, como se demostró un año más tarde cuando ni siquiera en la ciudad de Cádiz se había aplicado esta iniciativa, por lo que se decretaron una contribución directa y otra indirecta, en sustitución de la extraordinaria de guerra. ${ }^{7}$ Las Cortes, el 6 de julio de 1813 a través de su comisión de hacienda, retomaron con decisión la ardua tarea de levantar una «Hacienda Nacional», presentando un proyecto de ley que recogía, con mínimas alteraciones, la línea de trabajo reformista alentada desde la Junta Central. Entonces, el decreto de 13 de septiembre de 1813, bajo el título «Nuevo plan de contribuciones públicas», vino a sentenciar la incompatibilidad del «régimen antiguo» con el sistema constitucional y a establecer un sistema de contribuciones públicas, en sintonía con el Estado liberal que se pretendía consolidar. ${ }^{8}$

Salvo contadas singularidades, quedaron extintas todas las contribuciones impuestas sobre consumos, conocidas bajo las denominaciones genéricas de rentas provinciales y agregadas, así como las rentas estancadas, ya mayores, ya menores. Y, en su lugar, se estableció una contribución directa que debería corresponderse con las facultades económicas de los contribuyentes, sin excepción, y que se distribuyó sobre la riqueza total «conforme a la que posea cada provincia, cada pueblo y cada individuo».

5 Comín, 1996, 72-74.

6 Decreto LII, 1 de abril de 1811, Colección de los decretos y órdenes, 1820, I, 116.

7 Decreto CXLVI, 10 de abril de 1812, Ibidem, II, 183.

8 Decreto CCCIV, 13 de septiembre de 1813, Ibidem, IV, 229-237. 
Como se recogió en el artículo XII del decreto: «la riqueza nacional se considerará compuesta de tres ramos o elementos, territorial, industrial y comercial; y con esta distinción se asignará a cada provincia, a cada pueblo y a cada contribuyente su respectivo cupo»..$^{9}$ Asimismo, ante la ausencia de series actualizadas, se tomó como base de la riqueza territorial e industrial el Censo de Frutos y Manufacturas de 1799 y, como tabla tentativa de la actividad comercial, se optó por el estado comparativo presentado el 22 de agosto de 1813 en comisión extraordinaria de hacienda. Finalmente, las Diputaciones provinciales y los Ayuntamientos se erigieron en las instituciones claves para el desenvolvimiento del nuevo sistema fiscal, que, por una parte, debía conciliar el pretendido esfuerzo centralizador con la unificación de los viejos encabezamientos castellanos y los equivalentes aragoneses, y, por otra, tenía que impulsar la recaudación mediante una continua actualización estadística que permitiese alcanzar el insoslayable objetivo de la suficiencia fiscal.

Sin embargo, la pronta caída del régimen liberal devolvió al limbo el proyecto pergeñado y la vuelta al absolutismo no detuvo el ya prolongado proceso de decadencia recaudatoria. En 1816, siendo ministro de Hacienda Martín de Garay, se gestó, aunque de manera menos atrevida, un nuevo impulso fiscal. Si por un lado evitó eliminar los «estancos», por el otro propuso la sustitución de las rentas provinciales por la Contribución General del Reino, proporcional a la riqueza de los contribuyentes y que se aplicaría en todas las poblaciones, con excepción de las capitales de provincia y puertos principales, donde operarían los «derechos de puertas». ${ }^{10}$ Pero igual que ya había ocurrido con iniciativas precedentes, nunca acabó por elaborarse la indispensable «Estadística del Reino»y, sin base de repartimientos, el proyecto volvió a descarrilar. Las resistencias, tanto campesinas, huidizas de una revitalización de la presión hacendística, como nobiliarias y eclesiásticas, temerosas de la pérdida de los privilegios fiscales, supusieron decididos frenos para cualquier replanteamiento reformista.

El 1 de enero de 1820, tras el pronunciamiento de Riego en Cabezas de San Juan, se abrió para España la segunda etapa liberal, dando la oportunidad a los proyectos gaditanos de hacerse realidad a través de la acción del gobierno. Y los de hacienda no fueron una excepción. El Trienio Constitucional fue cauto en la senda de la reforma, poniendo el énfasis en una política económica amplia y coherente que permitiera alinear el crecimiento

9 Ibidem, 233.

10 Artola, 1998, 99-108. 
económico y la estructura fiscal. ${ }^{11}$ Los decretos de junio de 1821 erigieron las líneas maestras de un nuevo sistema fiscal, que mantuvo las coordenadas de 1816 e incorporó innovaciones tributarias deudoras de la fiscalidad francesa. ${ }^{12} \mathrm{El}$ sistema de 1821 tuvo como hitos primordiales las siguientes contribuciones, derechos y estancos: directa sobre predios urbanos y rústicos (contribución territorial y pecuaria en el presupuesto de 1822), de consumos, de registro y papel sellado, de la sal, del tabaco y de patentes, con el objetivo de gravar las actividades comerciales e industriales. ${ }^{13}$

El sistema fiscal del Trienio no tuvo un inicio prometedor, pues los déficits que se fueron sumando, ejercicio tras ejercicio económico, debieron ser acomodados en la negociación de empréstitos extranjeros sobre la base de las desamortizaciones. Sin embargo, el abrupto final de la experiencia liberal, abortada tras la invasión de los Cien Mil Hijos de San Luis, impedirá una adecuada evaluación de las medidas adoptadas. ${ }^{14}$

\section{Un gobierno político-militar para un tiempo nuevo}

Hasta el presente, todas las interpretaciones relacionadas con el Motín de Aznapuquio han puesto el acento en las discrepancias personales entre los dos protagonistas del momento —el virrey Joaquín de la Pezuela y el teniente general José de la Serna-, así como en las profundas diferencias que ambos manifestaron con relación a la conducción de la guerra. Las escasas fuentes documentales disponibles han permitido recrear la trayectoria biográfica de ambos personajes. ${ }^{15}$ Pezuela y La Serna compartieron en el Perú responsabilidades, uno como virrey y otro como comandante en jefe del Alto Perú desde 1816 hasta 1821, dejando numerosas pruebas que evidenciaron una tortuosa relación personal y escasa sintonía en cuanto a la dirección militar. ${ }^{16}$ Prueba de ello fueron los continuos desencuentros con relación a las campañas del Alto Perú, las fallidas expediciones de Chile

11 Prieto y De Haro, 2012, 140.

12 Sin embargo, para el gobierno político-militar del virrey La Serna en Lima, la normativa de referencia fueron los decretos gaditanos ya que la legislación fiscal del Trienio no llegará al Perú hasta finales de 1821, con el gabinete ya establecido en el Cuzco.

13 Decreto LXX, Contribución directa predios urbanos y rústicos; Decreto LXXII, Contribución sobre patentes; Decreto LXXIII, Reglas para la contribución sobre consumos; Decreto LXXVI, Condiciones reglamentarias para la venta de tabacos; y Decreto LXXVII, Contribución de registro, de 29 de junio de 1821, Colección de los decretos y órdenes, 1821, VII, 245-298.

14 Moral, 1975, 209-211.

15 Torata, 1895. Torrente, 1829-1830. García Camba, 1846. Luqui-Lagleyze, 2006.

16 Albi, 2009, 305-316. 
y la respuesta a la expedición de San Martín contra el corazón del virreinato. El carácter y los autores de las fuentes disponibles nos han procurado una interpretación sesgada del Motín de Aznapuquio, presentándolo como el resultado de un debate dentro del ejército entre viejos y nuevos militares, entre jóvenes oficiales, con bríos renovados con los que continuar el esfuerzo de la guerra, y un virrey agotado por el continuo cuestionamiento personal y derrotado por una realidad militar que lo sobrepasó, llevándolo a la inacción. Asimismo, el pronunciamiento del Ejército y el desplazamiento del virrey vendrían a desbloquear la decisión ya meditada por el Estado Mayor de evacuar Lima y buscar una nueva base de operaciones desde la que tomar la iniciativa y reorientar la guerra en el Perú. ${ }^{17}$

Este relato nos ha sido revelado por los testimonios disponibles en varios repositorios, tanto españoles como peruanos, pero su perfil eminentemente militar, junto a la extraordinaria escasez de documentación relativa a la acción de gobierno del último virrey, como podría haber sido la Memoria de Gobierno, han dejado en penumbra ámbitos políticos y económicos imprescindibles para poder analizar en su conjunto la realidad de un nuevo gobierno que se impuso al pasado. A estas carencias hay que sumar el estrago que supuso el conflicto bélico en cuanto a la pérdida y destrucción, para el período comprendido entre 1821 y 1824 , de documentos de toda índole, cercenando seriamente las posibilidades de investigar la época del último virreinato desde visiones alternativas. Así pues, las dificultades derivadas de la ausencia de documentación inédita, han mantenido a los especialistas, hasta el momento, en un estresante y rígido bucle. ${ }^{18}$

$\mathrm{Y}$ en este sentido cobra importancia la documentación custodiada en el Archivo General de la Nación y en el Archivo Histórico de la Municipalidad de Lima, inventariada en sus fondos coloniales. Los papeles analizados permiten aflorar rasgos políticos del gobierno del virrey La Serna, directamente relacionados con la política fiscal y desarrollados durante el período comprendido entre febrero y julio de 1821, ignorados hasta el momento y en los que se evidencia una notoria influencia del ideario liberal en la acción del último gobierno colonial.

Tras el pronunciamiento del 29 de enero, y una vez depuesto el virrey Pezuela sin trastornos ni notorias resistencias, el gobierno político-militar

17 Para Anna en noviembre de 1820 la posibilidad de abandonar la capital empezó a ser valorada mayoritariamente por la oficialidad: «La pérdida de la Esmeralda convenció al resto de comandantes realistas de que no valía la pena retener Lima» (Anna, 2003, 218).

18 Martínez Riaza, 2014, 121-143. 
comenzó su andadura con el decidido objetivo de la estabilidad, dando respuestas a lo que la declaración formal de los comandantes del ejército en Aznapuquio calificó de «errores políticos y militares». El abanico de iniciativas que habían acabado por orillar el liderazgo de Pezuela hasta la marginalidad, en opinión de la mayoría del Estado Mayor realista, era amplio e incluía denuncias sobre fallidos nombramientos, injustos reconocimientos, malversación de fondos, ineficaces medidas contra el contrabando y el comercio ilícito e inadecuada política fiscal, llegando incluso a la acusación de carecer de la más absoluta falta de pulso militar. ${ }^{19}$

El cambio debía traducirse en un punto de inflexión. Por una parte, el régimen debía evitar el desmoronamiento militar, que venía precipitándose desde noviembre de 1820, coincidente con el firme bloqueo de Cochrane y la audaz campaña de Arenales en diversas regiones, imprimiendo un ritmo distinto a la guerra. Y por otra, tenía la obligación de recuperar la iniciativa política con un profundo programa de regeneración y reorganización administrativa. Para ello, las acciones del gobierno se desplegaron con celeridad a tres niveles: el militar, con una serie de nombramientos en la cúpula dirigente, ${ }^{20}$ el político, enviando al coronel Seoane y al marqués de Valleumbroso a las Cortes españolas en misión oficial; ${ }^{21} \mathrm{y}$, por último, el institucional, apostando

19 La suspensión, por parte del virrey Pezuela, de la operación militar a gran escala planificada contra el Ejército de San Martín reestablecido en Huaura tras el falso movimiento en Retes, el día 27 de enero de 1821, acabó por posicionar en su contra a la totalidad de la alta oficialidad realista acampada en Aznapuquio.

20 Canterac fue designado general en jefe; Valdés, jefe de Estado Mayor, y Loriga comandante general de caballería. Albi, 2009, 317.

21 Informe de la misión del marqués de Valleumbroso y Antonio de Seoane, Madrid 16 de octubre de 1822, AGI, Indiferente General 313. Puente Candamo (1954, 426-428 y 439) fue pionero en el estudio detallado de esta misión, sobre la que nos informa, a partir de una apoyatura documental de primera mano: Escrito del marqués de Valleumbroso, dirigido a la Regencia, Archivo General de Indias (AGI), Estado, 74, 58; y Escrito del marqués de Valleumbroso al rey, AGI, Estado, 74, 59. Para más datos relacionados con la misión del marqués de San Lorenzo de Valleumbroso y el coronel Antonio de Seoane, véanse: Lohmann, 1993, 160-161, vol. II; Rizo Patrón, 2001, 422-424; Rosas Siles, 1995, 226; Tauro, 1987, 2315-2316, tomo VI. El alcance político de esta misión queda perfectamente demostrado si atendemos a que el objetivo fundamental de ambos en España, aparte de informar de primera mano a la Monarquía sobre lo acaecido en Aznapuquio, consistió en justificar el carácter y las singulares motivaciones de sus actores, junto a reafirmar la general inquebrantable fidelidad de los peruanos a su monarca, que no resultaba menor que la que le profesaba el ejército realista. No faltaron halagos a La Serna, «conocido tanto por sus talentos y virtudes como por la calidad y extensión de sus servicios», y al que el propio monarca había nombrado en primer lugar para suceder al virrey Pezuela, en caso necesario. Mera (2005) recurre a Gaspar Rico y Angulo, editor de «El Depositario», para asegurar que el motín y la consiguiente deposición del virrey Pezuela fue algo inesperado, extraño e inaudito, aunque no parece albergar duda alguna sobre que la llegada de La Serna al solio virreinal fue saludada «con un extraordinario regocijo», sin brote alguno de descontento, aunque a la sociedad limeña este insólito acontecimiento le hubiese producido asombro y extrañeza. 
por un sistema de gobernanza, en sintonía con el mandato de la Constitución de Cádiz.22 Con respecto a este último punto, fue de la mayor relevancia el decreto de 23 de junio de 1813 en el que se detallaban las «instrucciones para el gobierno económico-político de las provincias» y en el que el eje de la acción gubernativa pivotaba sobre los ayuntamientos, las diputaciones provinciales y los jefes políticos. ${ }^{23} \mathrm{El}$ decreto confirió a los ayuntamientos amplias facultades en torno a obras e infraestructuras, fomento de la actividad en cualquiera de sus vertientes, beneficencia, instrucción pública, elaboración de censos y salud pública, así como en lo referido al repartimiento y recaudación de contribuciones. Asimismo, debían rendir anualmente cuentas documentadas a la diputación provincial a través del jefe político. ${ }^{24}$

A la diputación provincial se le impuso la obligación del repartimiento de las contribuciones aprobadas entre los ayuntamientos bajo su intervención y de la supervisión de los fondos de Propios y Arbitrios de los pueblos. Y a su función fiscalizadora desempeñaba competencias similares a las de los ayuntamientos, pero a nivel provincial: conservación de las obras públicas, beneficencia, estímulo de la actividad económica y elaboración de estadísticas.

Así pues, la coordinación entre los ayuntamientos y la diputación provincial debía ser lo más ágil posible para la cogestión eficaz de funciones superpuestas en niveles territoriales diferenciados. Por último, el jefe político, que en el caso del Perú y atendiendo al artículo V coincide con la «Comandancia de las armas» al tratarse de un territorio amenazado de guerra, desempañaba la función principal de ejecutor de las «leyes y órdenes del Gobierno» y actuaba, a modo de gozne, entre las autoridades de los ayuntamientos y la diputación provincial.

\section{La negociación fallida}

Una vez que La Serna tomó las riendas del gobierno político-militar en Lima, sus esfuerzos se centraron en la consolidación del poder. Al envío

22 Es ilustrativa en este sentido la notificación por parte del virrey, con fecha 12 de febrero de 1821, de reimprimir y difundir la Constitución de Cádiz a todas las corporaciones y autoridades públicas de Lima y provincias, sin excepción. Este dato indica que, o bien no se había procedido con el debido entusiasmo en la etapa de Pezuela, o el nuevo gobierno quería imprimir su sello particular. Archivo General de la Nación (AGN), Superior Gobierno, Comunicaciones, Borradores del Virrey, GO-CO1 198, $2643,1$.

23 Decreto CCLXIX, «Instrucción para el gobierno económico-político de las provincias», de 23 de junio de 1813, Colección de los decretos y órdenes, 1820, IV, 105-126.

24 Castro, 1979. 
inmediato a España del marqués de Valleumbroso y el coronel Seoane, con la intención de lograr el reconocimiento oficial de las nuevas autoridades por parte de las Cortes y el despacho urgente de fuerzas de combate marítimas, se sumó el traslado de 1.500 hombres que, al mando de Valdés, tuvieron como objetivo reforzar a Ricafort en las provincias del interior y mantener libre la vía de suministros entre Lima y el Cuzco. Entonces tocaba gobernar en la confusa y enredada Lima y comprobar si la renovada propuesta política permitiría asentar al régimen. La Serna se enfrentaba a la ecuación de la fuerza y el dinero en el peor escenario posible. Tenía ante sí la tarea de lograr, por un lado, la mayor cantidad de fondos, mediante las reformas fiscales que fuesen precisas, con los que garantizar la pervivencia de su gobierno y del aparato burocrático sobre el que se sustentaba; ${ }^{25}$ y por otro, hacerlo posible exclusivamente mediante la negociación política, dejando de lado el uso de la fuerza, en momentos en que el Ejército debía tratar de hacer frente a un adversario militar que, día a día, seguía cerrando el cerco sobre la ciudad y sus áreas de influencia.

Las diversas instituciones debían tejer un acuerdo político de nueva planta, del que no existían precedentes en los que apoyarse, habida cuenta del singular acatamiento que el virrey Abascal prestó a la Constitución de la Monarquía Española ${ }^{26}$ durante su mandato. Y las instituciones llamadas a entenderse en el tablero político fueron: el Ayuntamiento constitucional, la Diputación provincial, la jefatura política y militar y, de forma complementaria, el Tribunal del Consulado.

El cabildo de Lima había sufrido una profunda reestructuración tras las elecciones del 7 de diciembre de 1820 quedando como alcaldes: el conde de San Isidro y José María Galdiano; como regidores, Francisco Zárate, Simón Rávago, Diego de Aliaga, el conde de la Vega del Ren, Francisco Vallés, el marqués de Corpa, Pedro de la Puente, José Manuel Malo y Molina, Francisco de Paula Mendoza, Mariano Vásquez, Manuel Pérez de Tudela, Manuel Sáenz de Tejada, Juan Bautista Gárate, Manuel María del Valle, Miguel Vértiz y Manuel Alvarado; y como síndicos, Tiburcio José de la Hermosa y Antonio Padilla. ${ }^{27}$

25 Lejos quedaba el esfuerzo de reordenamiento fiscal que supuso la Ordenanza de Intendentes de 1803, impulsada, entre otros altos funcionarios, por Joaquín Bonet y Abascal, quién años después (1816) ocuparía el cargo de contador mayor del Tribunal de Cuentas. Moreno, 1977, 726. Los últimos grandes acuerdos fiscales entre el gobierno y las élites locales fueron los que articularon la reforma de 1815. Contreras, 2002, 133-144. Flores Guzmán, 2010, 331-334.

26 Hamnett, 2010.

27 Anna, 2003, 223. 
Por su parte, la Diputación provincial de Lima había sido restablecida tras el nombramiento de una Junta Preparatoria por parte del virrey Pezuela, en cumplimiento del precepto constitucional. ${ }^{28}$ Y según Martínez Riaza: «sabemos sin duda que la de Lima se reinstala el 20 de septiembre de 1820 [...], presentes Bartolomé María de Salamanca (intendente interino de Lima), Francisco de Moreyra (por Lima), Manuel Bermúdez (por Tarma), Camilo Márquez (por Huancavelica), Nicolás Arancibar (por Arequipa) y los suplentes Antonio Bedoya y Manuel Cebada». ${ }^{29}$ La máxima autoridad política y militar, el virrey, ejercía sus funciones con el estimable apoyo de una secretaría ocupada por el coronel Eulogio de Santa Cruz. ${ }^{30}$ Y finalmente desempeñaría un notable papel en el tablero de las negociaciones, poniendo en valor su histórica posición en la política virreinal, el Tribunal del Consulado, dirigido a la sazón por su prior Manuel Gorbea y Badillo y los cónsules Antonio José de Sarroa y Manuel de Barreda, cuyo papel en el motín de Aznapuquio sigue siendo motivo de vivos debates. ${ }^{31}$

En un marco militar, político y económico poco halagüeño, el nuevo gobierno se puso en marcha con la tarea de imprimir un giro sustancial a una realidad que ineludiblemente conducía a la disolución del poder realista. ${ }^{32}$ La precaria situación no dejaba lugar a dudas, y tanto el grave problema de la escasez de provisiones como la falta de recursos generaban quebraderos de cabeza, difíciles de sortear. Los informes con los que contó el gobierno a finales del mes de febrero fueron poco alentadores, sobre todo si comparamos esos datos con los ofrecidos en un balance municipal de Lima en las postrimerías del siglo XVIII. ${ }^{33}$

Los responsables de la confección de los resúmenes de las disponibilidades de trigo, maíz y harinas, que describían una ciudad que caminaba

28 Peralta, 2011, 731.

29 Martínez Riaza, 1992, 685.

30 Colección Documental de la Independencia del Perú, 1973, XXII-3, 8.

31 Marks, 2007.

32 La ciudad a inicios de 1821 revelaba una crítica situación, lastrada por una crisis económica, social y política de largo aliento que había intensificado tras las graves derrotas de las campañas militares en Chile en 1818. Anna, 2003, 217-252. Para analizar el marco económico: Tepaske, 1986; Klein, 1998; Contreras, 2012, 420-426; De Haro, 2014, 288-298. Para el mosaico social: Flores Galindo, 1984. También es interesante como aproximación socio-económica: Anna, 1974.

33 Moreno, 1981a, 500 y ss. Con todas las reservas y cautelas necesarias, puede ayudar a iluminar el precario estado de cosas que se nos describe de la circunscripción limeña en los momentos en que se sitúa el presente trabajo, la comparación de sus resultados con los ofrecidos por un arqueo anterior en la Lima que estrenaba la reforma intendencial, donde se consignan los ingresos y gastos del cabildo de esa capital. 
peligrosamente hacia el desabastecimiento, ${ }^{34}$ fueron los diputados de los valles circundantes de Lima y los jueces tenientes de policía, correspondientes a los cuatro cuarteles de la ciudad, una división territorial de la capital, vigente desde fines del siglo XVIII, que no era la primera vez que se utilizaba para estos menesteres. ${ }^{35}$

El gobierno, sin demora, dio comienzo a las conversaciones. Durante la primera mitad del mes de febrero, exactamente entre los días 1 y 13, las negociaciones entre el virrey, la diputación provincial y el cabildo se redujeron a tímidos tanteos. El día 1 se discutieron en la corporación municipal dos oficios del virrey. Uno, relativo al nombramiento de dos individuos del ayuntamiento que, junto con un ministro de la Hacienda Nacional y bajo la presidencia del marqués de Valleumbroso, debían proceder en el plazo de 8 días a la recluta, contra abonos garantizados por la misma Hacienda, de 1.500 esclavos para el reemplazo en los «Cuerpos» de Burgos y Arequipa. Y otro, encargando la designación de un comisionado para el depósito de 1.000 caballos con destino al Ejército. Para la ejecución del primer repartimiento fueron elegidos, entre los principales hacendados, Pedro de la Puente y Juan de Echevarría, y, para el segundo, Manuel María del Valle. ${ }^{36}$ El alcalde, conde de San Isidro, cinco jornadas más tarde trasladó un nuevo oficio del jefe político y militar, informando sobre la reducción de su sueldo a doce mil pesos anuales, medida concebida como parte de un plan de ajuste en la administración y con la intención de que el ejemplo cundiese en el resto de los ramos públicos. ${ }^{37}$ Sin solución de continuidad, al día siguiente, otro oficio del virrey, reproduciendo una real orden, transmitió el

34 «Estado de víveres», Archivo Histórico de la Municipalidad de Lima (AHML), Fondo Colonial, Tesorería Propio y Arbitrios, 21.

35 Moreno, 1981b, 103 y ss. La división de la capital del virreinato en 4 cuarteles y 40 barrios, así como su reglamento de policía, instrumentos de fiscalización social, pero sobre todo de control económico, tiene su origen en las reformas llevadas a cabo en Perú por el inquieto y muy esforzado Jorge de Escobedo y Alarcón, visitador general que sucedió en Lima al controvertido José Antonio de Areche (Fernández Alonso, 1992). En la Colección Mata Linares de la Real Academia de la Historia (RAHML), CXII, 134-153, así como en AGI, Lima, 915, encontramos sendos ejemplares del impreso titulado División de cuarteles, calles y barrios e instrucción para el establecimiento de alcaldes de barrio en la capital de Lima. 1785. El padre de la reforma fue el conde de Aranda, sin olvidar el papel jugado en estas novedades por el limeño Pablo de Olavide; ambos propulsaron estas innovaciones, como se reconoce en los documentos consultados, sin olvidar lo acometido en Madrid. El visitador Escobedo fijó por bando la reforma el 23 de junio de 1785, siéndole aprobada por real cédula, fechada en Aranjuez, a 10 de abril de 1786 (RAHML, CXIII, 417-422).

36 Actas de cabildo, AHML, Fondo Cabildo Colonial, Libro de Cabildo 44 1814-1820, CLAC 45,43 r.

37 Ibidem, 44, 5 de febrero de 1821. El cabildo contestó oficialmente que ningún miembro de la corporación cobraba por entonces sueldo ni emolumento alguno. 
ofrecimiento de la Hacienda Nacional para habilitar los fondos necesarios, con calidad de reintegro por los ayuntamientos y diputaciones provinciales, para que los diputados elegidos a Cortes Generales de la Nación pudieran realizar su traslado a la Península. ${ }^{38}$

El 9 de febrero la corporación sondeó al gobierno en torno a la controversia del comercio libre. Sobre la base de las críticas circunstancias en las que se hallaban los depósitos de grano y harinas en la ciudad a causa del bloqueo patriota, apeló en oficio remitido a La Serna al tráfico sin restricciones, utilizando buques neutrales en la forma contemplada por los Decretos de las Cortes de 22 de marzo y 19 de septiembre de $1811 .{ }^{39} \mathrm{Y}$ en la siguiente jornada, según oficio del virrey, ya ejecutado por la Junta de Subsistencia, se procedió a la designación de Simón Rávago y Mariano Vázquez como comisionados para proceder al reparto y extracción de las reses necesarias entre los principales fundos, a fin de abastecer al Ejército durante un mes. Sin embargo, en este punto comenzaron a aflorar ciertas reticencias relacionadas con el previsible agotamiento de la producción agropecuaria y con la consiguiente caída de su producción que, de consumarse, conllevaría nefastas consecuencias para el futuro abastecimiento de la capital. A tales efectos se aconsejaba la requisa de ganado en las lomas de Atiquipa, lejos de los principales fundos y sin costes para los propietarios. ${ }^{40} \mathrm{Y}$ por último, el día 13 se trasladó al cabildo el contenido del oficio virreinal que dotaba un fondo, destinado a inválidos y familiares de soldados fallecidos en la guerra, a cargo de las rentas situadas en los ramos de tabacos, presas y decomisos, que hasta el momento disfrutaban los virreyes. ${ }^{41}$

Hasta aquí las comunicaciones no revelaron tensos debates entre ambas instituciones, pudiéndose afirmar que las controversias generadas y las temáticas discutidas fueron de bajo perfil. Pero todo cambió tras el acuerdo de 12 de febrero, mediante el que la Diputación provincial aprobó la contribución de guerra. Entonces, el gobierno extendió sendos oficios al Tribunal del Consulado y al Ayuntamiento constitucional. Al primero se dirigió con el ánimo de obtener recursos urgentes, apelando a la tradición y a su historia como «viejo aliado» del virreinato; y al segundo, con la esperanza de establecer una renovada alianza en base a un nuevo sistema fiscal.

38 Ibidem, 44r, 6 de febrero de 1821.

39 Ibidem, $44 \mathrm{r}$.

40 Ibidem, 44v, 10 de febrero de 1821.

41 Ibidem, $45 \mathrm{r}$. 
Según detalló la documentación oficial, el virrey, consciente de que el tiempo necesario para conseguir un profundo replanteamiento fiscal iba a ser largo, buscó cerrar un rápido acuerdo institucional con el Tribunal del Consulado. Esta maniobra le permitió plantear, sobre bases sólidas, la previsiblemente larga y dura negociación con el cabildo, contando con cierta suficiencia de recursos y con la fortaleza política que conllevaba tener a su favor una parte de la élite económica local.

Con fecha 15 de febrero La Serna abrió el cauce de negociación con el Tribunal del Consulado, solicitando un empréstito de 600.000 pesos, pagaderos en tres mesnadas. Expuso con claridad la situación de parálisis económica y comercial que sufría Lima y su entorno, y como, «cegados los manantiales» del Erario Público, la administración y el Ejército se asomaban peligrosamente al abismo. Asimismo, informó al Consulado de sus tres líneas de actuación, encaminadas conjuntamente a romper la dinámica de repliegue. La primera, solicitando «en acuerdo con la diputación provincial, el establecimiento de la contribución extraordinaria de guerra, sobre las bases en que las Cortes generales y extraordinarias de Cádiz la pusieron en práctica». La segunda, lanzando una ofensiva militar sobre las provincias del interior, con la que se lograría restablecer las líneas de comunicación entre la capital y el resto del virreinato. Y la tercera, impulsando un plan de racionalización económica que permitiese ahorrar ejemplarmente fondos y regenerar el aparato burocrático a todos sus niveles. Pero el virrey era consciente de que su plan requería de un tiempo del que no disponía, así lo expresó:

Pero estas medidas no pueden por si solas producir los efectos a que son dirigidas con la prontitud que demandan las circunstancias; y una de ellas es la contribución extraordinaria de guerra que no puede realizarse en menos de cuatro meses, contando con la actividad que tanto encargo al Excmo. Ayuntamiento de esta capital y a las demás provincias libres; y los otros arbitrios adoptados tampoco pueden sacarnos de apuros en estos tres meses, pues la situación lastimosa en que se encuentran los fondos públicos demandan algún tiempo para mejorarla. ${ }^{42}$

El escrito finalizaba solicitando el empréstito, dividido en tres mesadas de 200.000 pesos cada una, señalando para su primer recibo los días 20 o 25 del mes de febrero y garantizando su reintegro en base a los réditos que se esperaban de la planeada contribución extraordinaria de guerra.

42 AGN, Fondos Institucionales, Tribunal del Consulado, TC-GOB2, 4, 80, 1-2. 
El Tribunal del Consulado no demoró en trasladar su respuesta, que pudiéramos calificar, sin temor a equivocarnos, de extremadamente reflexiva y contenida. En reunión presidida por su prior, Manuel de Gorbea y los cónsules Antonio José de Sarroa y Manuel de Barreda, acordó por unanimidad, según se recoge en el acta del día 15 de febrero, ofrecer por vía de préstamo el servicio de 160 mil pesos, distribuidos en dos mesnadas de 80.000; una haciéndola efectiva el 20 o 25 de ese mismo mes, y la otra a lo largo del de marzo. Asimismo, animó al gobierno a que de la contribución de guerra, de la que debían ser exonerados los miembros del comercio, recaudase la cantidad restante hasta los señalados 600.000 pesos, distribuyéndola entre las demás corporaciones «o clases pudientes».43

El 19 de febrero, La Serna, vía oficio, transmitió al Consulado la aprobación de dicho acuerdo, manifestando la satisfacción del gobierno por el «leal servicio a la Nación del Cuerpo del Comercio». ${ }^{44}$ Y finalizó la comunicación poniendo en conocimiento del tribunal un proyecto, para su evaluación, que en fase de estudio por la Junta de Subsistencias, se ocupaba de la emisión de vales para su distribución en el circuito interior. ${ }^{45}$

Cerrado con la élite comercial este acuerdo, que aun con el recorte referido podíamos calificar de suficiente, las negociaciones con el cabildo discurrieron por sendas menos fluidas cuando el gabinete le presentó su proyecto «estrella», la contribución extraordinaria de guerra.

En sesión del 14 de febrero, de acuerdo con las normas que marcaban los cauces de comunicación entre el virrey, la Diputación provincial y el Ayuntamiento constitucional, este último presentó el oficio del virrey junto al acuerdo alcanzado por la diputación provincial, aprobando una nueva contribución, que tomó como referencia los decretos de $1 .^{\circ}$ de abril de 1811 y 3 de septiembre de $1812 .{ }^{46}$

Sin duda, la columna vertebral de la política fiscal del gobierno conmocionó a la élite local que, instalada en viejas fórmulas de negociación fiscal, observó incómoda como los vectores de autonomía y descentralización

43 Ibidem, 3-5.

44 Uno de los sectores sociales más afectados por la guerra de la Independencia del Perú y protagonista en las sucesivas evacuaciones de la capital fue el de los comerciantes españoles. Ruiz de Gordejuela, 2006, 468.

45 AGN, Fondos Institucionales, Tribunal del Consulado, TC-GOB2, 4, 80, 6.

46 Decreto LII de $1 .^{\circ}$ de abril de 1811 , Nueva forma de la contribución extraordinaria de guerra, Colección de los decretos y órdenes, 1820, I, 116-118. Decreto CXC de 3 de septiembre de 1812, Reglamento para verificar la contribución extraordinaria de guerra impuesta por decreto de $1 .{ }^{\circ} \mathrm{de}$ abril de 1811, Ibidem, IV, 229-237. 
quedaban seriamente alterados en el nuevo escenario. Los miembros de la corporación adelantaron su oposición a la referida contribución, calificándola de «inconveniente y demasiado gravosa», dando traslado del expediente a los síndicos procuradores municipales, encargados de la confección de una respuesta razonada.

La negociación había dado comienzo y las posiciones de partida estaban muy alejadas. ${ }^{47} \mathrm{El}$ cabildo «movió ficha» el 20 de febrero, remitiendo dos oficios al virrey. En el primero, debido a la deplorable situación en la que se encontraba la capital, reiteró la absoluta imposibilidad de hacer frente a la contribución. Y en el segundo, tomando como base el plan redactado por el síndico Tiburcio de la Hermosa, propuso, ante la ausencia de circulante y obstruidas las comunicaciones con las regiones mineras, la emisión de papel moneda en los términos contemplados por el Decreto de las Cortes de 31 de enero de $1811 .^{48}$

Pero el gobierno no estaba dispuesto a abandonar tan pronto su nueva propuesta fiscal. El 17 de marzo el virrey redobló la presión sobre el cabildo. En su sesión del 20, la corporación se vio obligada a dar los primeros pasos en cumplimiento del acuerdo de la Diputación provincial que, fundamentalmente, había determinado practicar, en el término de ocho días, el repartimiento de la contribución de 70.000 pesos, formando un padrón general de todos los habitantes de la capital, con un cálculo aproximado de sus riquezas. Asimismo, y con la intención de imprimir mayor celeridad a la elaboración del censo, se instó a excluir del mismo a «jornaleros y otros individuos de notoria insolvencia». El gobierno, contando con la colaboración del Tribunal del Consulado, que le facilitó amplia información económica de carácter municipal, ${ }^{49}$ concretó una cifra, que pudiera considerarse realista, aunque la coletilla de «por ahora», con que se cerraba el documento, dejaba abierta la posibilidad de nuevas exacciones, una vez obtenida la instantánea fiscal de la ciudad. Y el plazo y la metodología acordados para la elaboración del referido padrón general, evidenciaron una nítida influencia en el programa liberal gaditano, reconocible en los decretos emitidos.

47 Actas de cabildo, AHML, Fondo Cabildo Colonial, Libro de Cabildo 44, 1814-1820, CL AC $45,45 \mathrm{r}$

48 Podría tratarse del mismo proyecto al que el virrey La Serna hizo referencia al Tribunal del Consulado con fecha de 19 de octubre de 1821. Ibidem, 47r.

49 Informe de la Contaduría de Predios urbanos y Tesorería del Consulado analizando el desenvolvimiento de la contribución indicada desde su inicio a 1821, AGN, Archivo Colonial, Fondos Institucionales, Real Hacienda, Contaduría General de Tributos, 3, 58. 
A regañadientes, el cabildo acabó nombrando a los comisionados. Para el primer cuartel a Manuel Sáenz de Tejada, Manuel Alvarado y al marqués de Corpa; para el segundo a Francisco Zárate, Francisco Vallés y Juan de Echevarría; para el tercero, Mariano Vásquez Vargas, Miguel Vértiz y al conde de la Vega; y para el cuarto, a Pedro de la Puente, José Manuel Malo y Molina y Manuel María del Valle..$^{50}$ En tanto, la confrontación con la máxima autoridad devino en un ambiente cada vez más enrarecido, como lo demostró el tono del oficio remitido al virrey, instando a su secretaría de cámara la remisión al ayuntamiento «de los bandos que se publiquen, como se ha observado siempre, y cuya falta se advierte de algún tiempo a esta parte». ${ }^{51} \mathrm{Y}$ en este mismo sentido se sumaron las quejas por el cese de la Junta de Beneficencia.

Asimismo, el cabildo se tomó «un tiempo» para la elaboración de los padrones, del que el gobierno no disponía. Mientras los comisionados iban examinando los censos correspondientes a los cuarteles de la capital, ${ }^{52}$ con el objeto de ir conformando la contribución, justificaban la dilatación del proceso por las dificultades derivadas de la evaluación individualizada, aconsejando reorientar la contribución en términos tradicionales, por la vía del repartimiento, en base a corporaciones, comercio y gremios.

Pero el gobierno cortó en seco la discusión en torno a la naturaleza de la nueva iniciativa fiscal. En sesión del 12 de abril se debatió en la corporación el plan económico encargado de dividir por clases a los vecinos de la capital. El proyecto, que consistió en una adaptación de la tabla adjunta al Decreto LII de $1 .^{\circ}$ de abril de 1811, señaló cinco clases, en función de las rentas líquidas anuales del contribuyente, sobre las que se aplicaría un tanto por ciento con criterio de progresividad. ${ }^{53}$ Con respecto al decreto gaditano, la propuesta que se concretó elevaba el mínimo exento y reducía sustancialmente el tanto por ciento aplicable a las rentas más altas. Aun así suponía una reforma físcal sin precedentes en la historia del virreinato:

50 Actas de cabildo, AHML, Fondo Cabildo Colonial, Libro de Cabildo 44, 1814-1820, CL AC 45, 51v.

51 Ibidem, 51v.

52 El primero en analizarse para proceder a la distribución de la contribución fue el tercer cuartel en sesión de 23 de marzo, al que siguió el segundo en sesión del 4 de abril. Para el estudio de los padrones el período comprendido entre fines del siglo XVIII y el último cuarto del XIX «sigue siendo tierra de nadie con censos parciales». Gootenberg, 1995, 5.

53 Tabla. Colección de los decretos y órdenes, 1820, I, 119. 
DIONISIO DE HARO ROMERO Y ALFREDO MORENO CEBRIÁN

TABLA 1

CLASES, RENTAS Y TANTO POR CIENTO QUE CORRESPONDE

\begin{tabular}{|l|c|c|}
\hline \multicolumn{1}{|c|}{ Clase } & Renta (en pesos) & $\begin{array}{c}\text { Tanto por ciento } \\
\text { en las rentas }\end{array}$ \\
\hline Primera & $300-1900$ & $4 \%$ \\
\hline Segunda & $2.000-3000$ & $6 \%$ \\
\hline Tercera & $5.000-8.000$ & $8 \%$ \\
\hline Cuarta & $8.000-20.000$ & $10 \%$ \\
\hline Quinta & $20.000-[\ldots]$ & $12 \%$ \\
\hline
\end{tabular}

Fuente: Actas de cabildo, AHML, Fondo Cabildo Colonial, Libro de Cabildo 44, 1814-1820, CL AC 45, 58v.

El cabildo reaccionó con rapidez, y con el objetivo de aliviar la escasez de fondos públicos, articuló dos medidas alternativas a la contribución. Una, consistente en impulsar la liberalización del comercio a través de un buque neutral que, con carácter mensual, permitiese la recuperación del pulso comercial y facilitase la revitalización de las rentas de la Aduana a través del cobro de los aranceles. Y otra, diseñada por el síndico procurador Tiburcio de la Hermosa, planteada tentativamente en el mes de febrero, fundada en la emisión de 500.000 vales. ${ }^{54}$ Esta última propuesta, aprobada por La Serna, será recuperada, aunque con matices, en tiempos del Protectorado, con la creación por parte del ministro de Hacienda del momento, Hipólito Unanue, del Banco Auxiliar de Papel Moneda. ${ }^{55}$

El proyecto emisor de vales, una vez estudiado por la Diputación provincial, que contó con el asesoramiento del Tribunal del Consulado, ${ }^{56}$ se concretó el 14 de abril en la orden de impresión de 500.000 pesos en vales de $50,100,200,300,400$ y 500 pesos, que con el premio del $8 \%$ perseguía el afloramiento de los caudales atesorados, precisos para revitalizar la circulación monetaria. Las Cortes, según la Gaceta de Madrid de 13 de octubre de 1820, habían habilitado esta vía de financiamiento con la creación de pagarés, de 2.000 reales de vellón cada uno, con un interés del 10 al $12 \%$, a cargo de la Tesorería General. El plan fue concebido para un plazo

54 Actas de cabildo, AHML, Fondo Cabildo Colonial, Libro de Cabildo 44 1814-1820, CL AC 45, 60r.

55 De Haro, 2011 y 2013.

56 AGN, Fondos Institucionales, Tribunal del Consulado, TC-GO3, 22, 1455, 1-2. 
de dos años y la amortización del papel moneda se llevaría a cabo a través de los fondos que se liberarían con la venta de las fincas pertenecientes al ramo de Temporalidades y con los derechos de la extinguida Inquisición. El remate de las fincas hipotecadas, hasta la cantidad necesaria para cubrir este crédito, estaría dirigido por una comisión conformada por tres diputados, uno del Tribunal del Consulado, otro de los tenedores de billetes y, un tercero, designado por el gobierno, bajo la autoridad del Intendente. Los vales fueron ideados y dotados con amplia capacidad liberatoria. Las Cajas Generales, la Aduana, las Temporalidades y la Casa de Moneda pagarían, con una tercera parte en billetes y dos en numerario, los sueldos que excediesen de 600 pesos. Se contempló el pago de los réditos de las deudas, independientemente de su naturaleza, con los billetes emitidos, y se declaró la obligatoriedad de su admisión para cualquier pago, «sea cual fuese el giro, trato o negociación». En la ejecución del proyecto desempeñaría un papel central el Tribunal del Consulado, tomando a su cargo 200.000 pesos, repartiéndose el resto del papel entre las diferentes cajas nacionales. En cuanto a la controversia en torno al comercio libre con buques neutrales, el gobierno se limitó a citar el decreto de las Cortes que versaba sobre el arancel general de aduanas. ${ }^{57}$

Sin embargo, a fines del mes de abril, la negociación avanzó sin rumbo claro mientras el entorno político y militar no dejaba de deteriorarse. Las campañas militares diseñadas con el objetivo de abrir las líneas de suministros entre Lima y las provincias del interior, tras unos prometedores éxitos iniciales, acabaron agotándose con la acción erosiva de las montoneras y las operaciones de Miller y Arenales en el flanco sur de la costa. Asimismo, las sucesivas medidas desarrolladas por el gobierno, encaminadas a dinamizar la actividad agrícola y ganadera en los valles y fundos circundantes a la capital, no surtieron efecto alguno, limitando aun más los abastecimientos básicos para la población urbana.

Y especial atención merece la negociación abierta entre La Serna y el general San Martín en la hacienda de Punchauca, ${ }^{58}$ patrocinada por el enviado especial de las Cortes, el capitán de fragata Manuel Abreu, y para la que el virrey formó una «junta de pacificación». Las conversaciones se

57 «Los buques extranjeros se admitirán en todos los puertos de la Monarquía Española, conforme sean admitidos los buques españoles en los puertos extranjeros respectivos de cada nación en particular», Artículo 19 del Decreto XLVI de 5 de octubre de 1820, Colección de los decretos y órdenes, 1821, VI, 175.

58 Martínez Riaza y Moreno Cebrián, 2014, 122-134. Martínez Riaza, 2011, 660-661. Vargas Ugarte, 1929. 
iniciaron el 4 de mayo y alcanzaron su momento álgido el 2 de junio, con motivo de la entrevista entre La Serna y San Martín. La propuesta de paz lanzada por el general rioplatense, alimentando el ansiado final de la guerra, anhelado por sectores sociales cada vez más amplios, acabaron por romper el bloque realista cuando Abreu, Llano y Galdiano ${ }^{59}$ se inclinaron a aceptarla. El virrey frenó en seco el debate, implementando una contraoferta que eludía el reconocimiento de la independencia y que San Martín no tardó en rechazar. ${ }^{60}$ Así, el gobierno logró abortar un acuerdo que abría el camino a una independencia negociada, pero de un altísimo coste político: una crisis institucional al más alto nivel, que restaba potencia a un gobierno que no lograba sintonizar con la población en su propósito de consolidar un poder que se le escapaba día a día de sus manos. En un momento crucial de las negociaciones de Punchauca, el virrey disolvió el 23 de mayo la Junta de Subsistencias presidida por el conde de Villar de Fuente, circunstancia que acentuaría aun más el enfrentamiento entre el cabildo y La Serna.

A lo largo del mes de mayo no se experimentó avance alguno en torno a los arbitrios aprobados. La emisión de vales no se ejecutó y, a finales de ese mes, el cabildo dio por zanjadas las negociaciones con respecto a la contribución «liberal». Los padrones acabaron por ser completados y remitidos al gobierno el día 22, con un claro mensaje de ruptura. Los comisionados, argumentando en base a la «deplorable» situación en la que se hallaban los habitantes y sus rentas, remitieron al virrey los censos, que sumaban la «ridícula» cantidad de 16.406 pesos. ${ }^{61}$

El mensaje era claro: el gobierno no podía pretender imponer su acción política a buena parte de la élite limeña, por lo que las siguientes comunicaciones entre el virrey y el cabildo no hicieron sino ensanchar la ya insalvable brecha establecida. Un escrito anónimo, dirigido al alcalde, el conde de San Isidro, donde se ponían en entredicho las gestiones políticas del ayuntamiento desde su instalación, y que se pretendía fuese leído en cabildo pleno, vino a enrarecer aun más el contaminado ambiente político entre ambas partes. ${ }^{62}$

Y el oficio remitido al virrey, con fecha 6 de junio, denunciando los desórdenes y abusos cometidos por el ejército en diferentes haciendas y

59 Miembro de la Junta de pacificación a propuesta del cabildo de Lima.

60 Albi, 2009, 328-329.

61 Actas de cabildo, AHML, Fondo Cabildo Colonial, Libro de Cabildo 44 1814-1820, CL $\mathrm{AC} 45,62 \mathrm{r}$

62 Ibidem, $64 \mathrm{v}$ 
ramos de abastos, era una clara invitación al abandono. ${ }^{63} \mathrm{Y}$ ese fue el momento, ya sin alternativas, de proceder a la evacuación de la Ciudad de los Reyes. La Serna y buena parte de su Estado Mayor tenían grabada la amarga experiencia del segundo sitio de Zaragoza en la guerra de la Independencia española. Para ellos fue el final de su participación activa en el conflicto peninsular. En el primer semestre de 1821 se sumaron a los motivos militares, que aconsejaban desalojar una ciudad portuaria bloqueada por una escuadra marítima y hostigada desde el interior, las razones políticas de un gobierno en franco declive, incapaz de organizar a quien o a quienes no estaban dispuestos a hacerlo.

\section{Conclusión}

El gobierno político-militar del virrey La Serna sigue planteando sugerentes interrogantes en torno a su naturaleza. La ausencia de documentación oficial fundamental, como es el caso de las actas de la Diputación provincial y los números de la Gaceta del Gobierno de Lima correspondientes al primer semestre de 1821, nos obligó a avanzar con cautelas, manteniendo las dudas en torno al perfil liberal de La Serna y sus colaboradores más fieles. Pero las actas del cabildo de Lima, junto con otros fondos complementarios, nos han permitido empezar a analizar el último virreinato bajo un prisma alternativo, como lo demuestran las duras negociaciones que el gobierno impulsó con las élites locales en torno a un nuevo sistema fiscal que sustentaba su fuerza y legitimidad sobre los principios liberales de la carta gaditana.

Y aunque el escenario no era el propicio para la introducción de cambios de tan profundo calado, la guerra fue vista como la oportunidad para desbrozar los obstáculos que se oponían al establecimiento de un nuevo sistema de gobierno económico. En definitiva, el gobierno político-militar salido de Aznapuquio planteó una sugerente reorientación fiscal, capaz de permitir alcanzar la tan ansiada estabilidad política.

La nueva base fiscal requería de amplios acuerdos en los que el cabildo fue pieza fundamental. Tras las elecciones de diciembre de 1820, el nuevo perfil político del Ayuntamiento constitucional de Lima podría hacer pensar en la posibilidad de éxito de la iniciativa programada. Las negociaciones en

63 Idem. 
torno al nuevo sistema fiscal pivotaron con fuerza entre el virrey, en colaboración con la Diputación provincial, y el cabildo, mientras que el Tribunal del Consulado se mantuvo en un papel discreto de apoyo medido al gobierno virreinal. Sin embargo, intereses contrapuestos, la extraordinaria debilidad política del nuevo gobierno que acompañó a La Serna, junto al rápido deterioro de una ya de por sí frágil situación política y militar, acabaron por animar al gobierno al abandono de una ciudad reacia a adoptar medidas que consideró contrarias a sus intereses.

Pero los padrones se realizaron y la información que se desprendió de los mismos quedaría bajo la tutela de los sucesivos gobiernos, aflorando de forma intermitente a lo largo de una guerra que se extendería hasta diciembre de 1824. Asimismo, y aunque la investigación adolezca de una seria limitación como es sondear un tema tan complejo como representa la interacción entre finanzas públicas y política en una coyuntura tan breve como un semestre, estas medidas de política tributaria que en los tiempos de la independencia fueron tanteadas, más adelante, serán materias de vivos debates en las nuevas repúblicas sudamericanas.

Recibido el 3 de octubre de 2016 Segunda versión el 18 de enero de 2017

Aceptado el 19 de enero de 2017

\section{Referencias bibliográficas}

Albi, Julio, El último virrey, Madrid, Ollero y Ramos Editores, 2009.

Anna, Timothy E., «Economic Causes of San Martin's Failure in Lima», Hispanic American Historical Review, 54, 4, Durham, 1974, 657-681.

Anna, Timothy E., La caída del gobierno español en el Perú. El dilema de la independencia, Lima, Instituto de Estudios Peruanos, 2003.

Artola, Miguel, «Los orígenes de la contribución sobre la renta: de Ensenada a Mon», en Torre Campo, J. de la y García-Zúñiga, M. (eds.), Hacienda y crecimiento económico. La reforma de Mon, 150 años después, Madrid, Gobierno de Navarra / Marcial Pons, 1998, 99-108.

Castro, Concepción de, La Revolución Liberal y los municipios españoles, Madrid, Alianza Universidad, 1979.

Colección de los decretos y órdenes que han expedido las Cortes Generales y Extraordinarias, tomo I (24 septiembre 1810 a 24 septiembre 1811), tomo II (24 septiembre 1811 a 24 mayo 1812), tomo IV ( 24 febrero a 14 septiembre 1813), Madrid, Imprenta Nacional, 1820. 
Colección de los decretos y órdenes generales expedidos por las Cortes Ordinarias de 1820 y 1821, tomo VI (6 julio a 9 noviembre 1820), tomo VII (25 febrero a 30 junio 1821), Madrid, Imprenta Nacional, 1821.

Colección Documental de la Independencia del Perú, Tomo XXII, vol. 3, Documentación Oficial Española, Gobierno Virreinal del Cuzco, Lima, Comisión Nacional del Sesquicentenario de la Independencia del Perú, 1973.

Comín, Francisco, Historia de la Hacienda pública, II. España (1808-1995), Barcelona, Crítica, 1996.

Contreras, Carlos, «La reforma fiscal de 1815, las finanzas peruanas en vísperas de la independencia», Revista Economía, 25-50, Lima, 2002, 123-148.

Contreras, Carlos, «El precio de ser libres: costos y consecuencias económicas de la independencia en el Perú», en Mc Evoy, C.; Palti, E. y Novoa, M. (eds.), En el nudo del imperio. Independencia y democracia en el Perú, Lima, IFEAIEP, 2012, 417-441.

De Haro Romero, Dionisio, «La política monetaria de San Martín en el Perú», Revista de Indias, 71, 253, Madrid, 2011, 793-823.

De Haro Romero, Dionisio, «Papel para un Perú independiente: el pensamiento económico español y la creación del Banco Auxiliar de Papel Moneda», Revista Complutense de Historia de América, 39, Madrid, 2013, 203-227.

De Haro Romero, Dionisio, «De virreinato a nación: quiebra colonial y Estado sin Hacienda en el Perú», en Martínez Riaza, A. (ed.), La independencia inconcebible. España y la «pérdida» del Perú (1820-1824), Lima, Fondo Editorial de la PUCP e Instituto Riva-Agüero, 2014, 287-344.

Fernández Alonso, Serena, «Perfil biográfico y acción de gobierno de don Jorge Escobedo y Alarcón», Revista de Indias, 52, 195-196, Madrid, 1992, 365-384.

Fisher, John, El Perú borbónico 1750-1824, Lima, IEP Ediciones, 2000.

Fisher, John, «Redes de poder en el virreinato del Perú, 1776-1824: Los burócratas», Revista de Indias, 66, 236, Madrid, 2006, 149-164.

Flores Galindo, Alberto, Aristocracia y plebe, Lima, Mosca Azul, 1984.

Flores Guzmán, Ramiro, «Fiscalidad y gastos de gobierno en el Perú borbónico», en Contreras, C. (ed.), Compendio de Historia Económica del Perú, Tomo III, Economía del período colonial tardío, Lima, Banco Central de Reserva del Perú e Instituto de Estudios Peruanos, 2010, 295-376.

Fontana, Josep, La Hacienda en la Historia de España 1700-1931, Madrid, Instituto de Estudios Fiscales, 1980.

García Camba, Andrés, Memorias para la historia de las armas españolas en el Perú, Madrid, Sociedad Tipográfica de Hortelano y Compañía, 1846.

Gil Novales, Alberto, «La independencia de América en la conciencia española, 1820-1823», Revista de Indias, 157-158, Madrid, 1979, 235-265.

Gootenberg, Paul, Población y etnicidad en el Perú republicano (siglo XIX), Lima, Instituto de Estudios Peruanos, 1995. 
Hamnett, Brian, La política contrarrevolucionaria del virrey Abascal: Perú, 18061816, Lima, Instituto de Estudios Peruanos, 2000.

Hamnett, Brian, «El momento de decisión y de acción: El virreinato del Perú en el año 1810», Historia y Política, 24, Madrid, 2010, 143-168.

Klein, Herbert, The American Finances of the Spanish Empire. Royal Income and Expenditures in Colonial Mexico, Peru, and Bolivia, 1680-1809, Albuquerque, University of New Mexico Press, 1998.

Jensen, Silvina, «El problema americano en el Trienio Liberal. Análisis de las políticas de Ultramar de las Cortes españolas (1820-1823)», Trienio, 28, Madrid, 1996, 51-98.

Landa Arroyo, César, «El rol de la Constitución de Cádiz en la gestación de la independencia del Perú», Historia Constitucional, 13, Madrid, 2012, 315-337.

Lohmann Villena, Guillermo, Los americanos en las órdenes nobiliarias, Madrid, CSIC, 1993.

Luqui-Lagleyze, Julio Mario, Por el rey, la fe y la patria: el ejército realista del Perú en la independencia sudamericana, 1818-1825, Madrid, Ministerio de Defensa, 2006.

Lynch, John, Las revoluciones hispanoamericanas 1808-1826, Barcelona, Ariel, 1989 [1976].

Martínez Riaza, Ascensión, «Las diputaciones provinciales americanas en el sistema liberal español», Revista de Indias, 52, 195, Madrid, 1992, 647-691.

Martínez Riaza, Ascensión, «Para reintegrar la nación. El Perú en la política negociadora del Trienio Liberal con los disidentes americanos, 1820-1824», Revista de Indias, 71, 253, Madrid, 2011, 647-692.

Martínez Riaza, Ascensión, «Todos eran realistas. Liberalismo y absolutismo en el gobierno del Virreinato del Perú, 1820-1824», en Álvarez Cuartero, I. y Sánchez Gómez, J. (coords.), Visiones y Revisiones de la independencia Americana Realismo. Pensamiento conservador: ¿una identificación equivocada?, Salamanca, Ediciones Universidad de Salamanca, 2014, 121-143.

Martínez Riaza, Ascensión y Moreno Cebrián, Alfredo, «La conciliación imposible. Las negociaciones entre españoles y americanos en la Independencia del Perú (1820-1824)», en Martínez Riaza, A. (ed.), La independencia inconcebible. España y la «pérdida» del Perú (1820-1824), Lima, Fondo Editorial de la PUCP e Instituto Riva-Agüero, 2014, 99-212.

Martínez Torrón, Diego, Los liberales románticos españoles ante la descolonización americana (1808-1833), Madrid, Fundación Mapfre, 1992.

Marks, Patricia H., Deconstructing Legitimacy: Viceroys, Merchants, and the Military in Late Colonial Peru, Pennsylvania, Pennsylvania State University Press, 2007.

Mera Avalos, Arnoldo, «Cuando la patria llegó a la capital: el miedo ante el advenimiento de la Independencia», en Rosas, C. (ed.), El miedo en el Perú, Lima, Fondo Editorial de la PUCP, 2005, 139-166. 


\section{CONTRIBUCIÓN DE GUERRA Y NEGOCIACIONES: LA POLÍTICA FISCAL}

Moral, Joaquín del, Hacienda y sociedad en el Trienio Constitucional 1820-1823, Madrid, Instituto de Estudios Fiscales, 1975.

Moreno Cebrián, Alfredo, «La Descripción del Perú de Joaquín Bonet y la Ordenanza de Intendentes de 1803», Revista de Indias, 149-150, Madrid, 1977, 723-788.

Moreno Cebrián, Alfredo, «Un arqueo a la hacienda municipal limeña a fines del siglo XVIII», Revista de Indias, 165-166, Madrid, 1981a, 499-540.

Moreno Cebrián, Alfredo, «Cuarteles, calles y barrios de Lima a fines del siglo XVIII», Jahrbuch für Geschichte von Staat, Wirtschaft und Gesellschaft Lateinamerikas, 18, Colonia, 1981b, 97-161.

Ortemberg, Pablo, «La entrada de José de San Martín en Lima y la proclamación del 28 de julio: la negociación simbólica de la transición», Histórica, 83-2, Lima, 2009, 65-108.

Peralta Ruiz, Víctor, «El impacto de las Cortes de Cádiz en el Perú. Un balance historiográfico», Revista de Indias, 68, 242, Madrid, 2008, 67-96.

Peralta Ruiz, Víctor, «La pluma contra las Cortes y el Trono. La prensa y el desmontaje del liberalismo hispánico en el Perú, 1821-1824», Revista de Indias, 71, 253, Madrid, 2011, 729-758.

Prieto Tejeiro, Enrique y De Haro Romero, Dionisio, «La reforma monetaria del trienio liberal en España, 1820-1823: Modernización y límites», América Latina en la Historia Económica, 2-38, México, 2012, 131-161.

Puente Candamo, José de la, «La misión del Marqués de San Lorenzo de Valleumbroso y de Antonio Seoane», Revista Histórica, 21, Lima, 1954, 426-457.

Puente Candamo, José de la, La independencia del Perú, Madrid, Editorial Mapfre, 1992.

Rizo-Patrón Boylan, Paul, «Las emigraciones de los súbditos realistas hacia España durante la crisis de la Independencia», en O'Phelan Godoy, S. (ed.), La Independencia del Perú. De los Borbones a Bolívar, Lima, PUCP, 2001, 407-428.

Rodríguez, Jaime (coord.), Revolución, independencia y las nuevas naciones de América, Madrid, Editorial Mapfre, 2005.

Rosas Siles, Alberto, «La nobleza titulada del Virreinato del Perú», Revista del Instituto de Investigaciones Genealógicas, 21, Lima, 1995, 27-539.

Ruiz de Gordejuela Urquijo, Jesús, «La salida de la élite virreinal del Perú: sacerdotes, funcionarios y comerciantes, 1821-1825», Revista de Indias, 61, 237, Madrid, 2006, 453-472.

Sala i Vila, Nuria, «El Trienio Liberal en el Virreinato peruano: los ayuntamientos constitucionales de Arequipa, Cusco y Huamanga, 1820-1824», Revista de Indias, 71, 253, Madrid, 2011, 693-728.

Sánchez Andrés, Agustín, «La búsqueda de un nuevo modelo de relaciones en los territorios ultramarinos durante el Trienio Liberal (1820-1823)», Revista de Indias, 57, 210, Madrid, 1997, 451-474. 
Tauro, Alberto, Enciclopedia Ilustrada del Perú. Síntesis del conocimiento integral del Perú, desde sus orígenes hasta la antigüedad, Lima, PEISA, 1997, tomo VI.

Torata, Conde de (Fernando Valdés), Refutación que hace el mariscal de campo don Jerónimo Valdés del Manifiesto que el teniente general D. Joaquín de la Pezuela imprimió en 1821 a su regreso del Perú, Madrid, Imprenta de la viuda de M. Minuesa de los Ríos, 1895.

Torrente, Mariano, Historia de la Revolución Hispanoamericana, Madrid, Imprenta de Moreno, 1829-1830, 3 vols.

Tepaske, John, «General Tendencies and Secular Trends in the Economies of Mexico and Peru: The View from the Cajas of Mexico and Lima», en Jacobsen, N. y Puhle, H.J. (eds.), The Economies of Mexico and Peru during the Late Colonial Period, 1760-1810, Berlin, Colloquium Verlag, 1986, 316-339.

Vargas Ugarte, Rubén, «Las negociaciones de Punchauca», Boletín del Museo Bolivariano, 1-8, Lima, 1929, 285-299. 


\title{
Médicos, administradores y curanderos. Tensiones y conflictos al interior del arte de curar diplomado en la provincia de Santa Fe, Argentina (1861-1902)/
}

\author{
Doctors, Administrators and Curanderos. \\ Tensions and Conflicts among the Oficial Healing Art \\ in the Province of Santa Fe, Argentina (1861-1902)
}

José Ignacio Allevi ORCID iD: http://orcid.org/0000-0003-4819-1398

CONICET / ISHIR-CESOR / UNR, Argentina

Adrián Carlos Alfredo Carbonetti ORCID iD: http://orcid.org/0000-0002-2093-2046

CONICET / CIECS / UNC, Argentina

Paula María Sedrán ORCID iD: http://orcid.org/0000-0002-0592-0397

CONICET / ISHIR-CESOR, Argentina

El trabajo analiza una serie de recursos administrativos presentados ante las autoridades de la provincia de Santa Fe bien por los médicos diplomados para denunciar el ejercicio ilegal de la medicina — curanderismo- - bien por los vecinos para solicitar se autoricen este tipo de prácticas no permitidas. Nos interesa tensionar el proceso de medicalización social mostrando la pervivencia y legitimidad de ciertas prácticas sustentadas en saberes "populares», así como la incertidumbre de los saberes biomédicos. Por otra parte, discutiremos el proceso de profesionalización de los médicos como expertos «únicos» en la prestación de servicios de salud, al mostrar que las prácticas «alternativas» de curar eran en verdad la norma de los ciudadanos.

Palabras Clave: Curanderismo; Profesionalización; Medicalización; Argentina.

The paper analyzes a series of administrative appeals presented to the authorities of the province of Santa Fe either by qualified doctors to denounce the illegal exercise of medicine — known as curanderismo- as well as by neighbors to request authorization of this type of unallowed practices. We are interested in stressing the process of social medicalization by showing the survival and legitimacy of certain practices based on "popular» knowledges, and the uncertainty of biomedical knowledge. On the other hand, we will discuss the professionalization process of physicians as «unique» experts in the provision of health services, showing that «alternative» healing practices were indeed the norm of citizens.

Keywords: Curanderismo; Profesionalization; Medicalization; Argentina.

Copyright: (C) 2018 CSIC. Este es un artículo de acceso abierto distribuido bajo los términos de la licencia de uso y distribución Creative Commons Reconocimiento 4.0 Internacional (CC BY 4.0). 


\section{La profesión como punto de llegada: derivas de la legitimidad médica}

Este trabajo se propone constituir un aporte a las discusiones que renuevan constantemente el campo de la historia social y cultural de la salud y la enfermedad, al discutir la complejidad de dos procesos: la medicalización social, por una parte, y la profesionalización y legitimidad médica, por otra. ${ }^{1}$ De manera secundaria, entendemos que el problema de la legitimación y profesionalización de la medicina como saber hegemónico sobre la salud a partir de la tensión entre los diplomados y los sanadores empíricos puede aportar a otro campo de estudios. Nos referimos a la revisión historiográfica en torno al Estado como figura y actor omnicomprensivo, el cual ha sido revisitado y renovado en los últimos años en pesquisas que han enfatizado no solo la fragilidad de su tendido y la cuestión central de sus cuadros burocráticos, ${ }^{2}$ sino también el problema de los límites de la medicalización, en función de la efectividad de sus estructuras en el control y gestión de poblaciones tanto en zonas caracterizadas por la escasez de personal o de agencias específicas - problema estudiado para los Territorios Nacionales en Argentina-,${ }^{3}$ como también en las ciudades «centrales». En este sentido, nuestra propuesta responde a este tipo de inquietudes, en tanto la problemática del curanderismo se inserta en una miríada de planos desde los cuales observar cuestiones atinentes a la conformación Estado, a las modernizaciones sociales y al proceso de medicalización de distintas esferas de lo social.

La segunda mitad del siglo XIX en Argentina acarreó una serie de transformaciones que modificaron completamente el amplio espectro de la relación social: sociedad, Estado, economía y cultura, todos ellos atravesaron cambios sustanciales, a partir de lo que se entendió como procesos de modernización. ${ }^{4}$ Estos, sin embargo, no resultaron inocuos a todos los sectores sociales, y sus consecuencias derivaron en la emergencia de lo que numerosos estudios han entendido como «cuestión social». ${ }^{5}$

En este marco, los brotes epidémicos que azotaron a la población ingresaron en la agenda de la limitada acción del Estado, y con ello los médicos comenzaron a demandar un reconocimiento de su labor y su saber por este último. Como parte de este proceso de múltiples cambios, los médicos diplomados —inmigrantes, en su mayoría - fueron emergiendo

1 Carbonetti, Aizenberg y Rodríguez, 2014. Di Liscia, 2008. Armus, 2002.

2 Bohoslavsky y Soprano, 2010. Bohoslavsky y Godoy, 2010. Plotkin y Zimmermann, 2012.

3 Bohoslavsky y Di Liscia, 2008.

4 Bonaudo, 2007. Reguera, 2009.

5 Castel, 1997. Suriano, 2000. 
tímidamente como un actor que pretendía hegemonizar los sentidos y prácticas del arte de curar, frente a un número no menor de sujetos que tradicionalmente se habían abocado a estas tareas a partir de saberes empíricos y que contaban, además, con una legitimidad social considerable. ${ }^{6}$

Este grupo de médicos diplomados en vías de profesionalización era, a la sazón, parte de la elite local en los distintos espacios donde se encontraban, lo cual habilitó su posibilidad de ingresar en los espacios que en los distintos niveles del Estado fueron emergiendo para velar tanto por la salud de la población como por sus intereses corporativos — controlando títulos, habilitando farmacias y establecimientos de salud, etc.—. Los más relevantes en este sentido fueron el Departamento Nacional de Higiene y los Consejos de Higiene provinciales, instituciones nacidas al calor de crisis epidémicas o sanitarias que pugnaban por atender a una de las aristas de la cuestión social desde la higiene, así como también a resguardar el campo de acción de los diplomados e intentar construir progresivamente su monopolio. ${ }^{7}$ No obstante la ventaja relativa que suponía su vínculo con actores clave del Estado, como todo proceso, la profesionalización de la medicina fue un camino sinuoso y de múltiples vías, estudiado principalmente para el caso de Buenos Aires. ${ }^{8}$

Las dificultades de los diplomados en este sentido no eran menores, y si bien, por una parte, respondían a las limitaciones propiamente estatales en la capacidad - y voluntad - de control por sus instituciones y agentes, por otro lado no debemos perder de vista que tanto las intervenciones de la medicina académica o de las terapias populares-tradicionales eran inciertas en sus fundamentos y resultados, y así partir del hecho que la legitimidad de las prácticas médicas no superaba a la de curanderos, sanadores, hipnotistas, espiritistas, parteras, entre otros. Los estudios sobre la materia destacan que en el proceso de hegemonización médica fueron centrales las políticas de «des-calificación» y represión de prácticas que aparecían como «heterogéneas» frente a una supuesta homogeneidad y fortaleza del saber médico diplomado. ${ }^{9}$ En la disputa por la significación que los médicos debían librar para alcanzar no solo el monopolio de una práctica sino la legitimidad social de su saber, reconocemos dos aspectos analíticos: la definición simbólica de qué prácticas eran «efectivas» y, por otro lado, de cuáles serían «permitidas».

6 Di Liscia, 2003.

7 Prieto, 1996. Pascual, 2017. 2003.

8 González Leandri, 1999; 2012. Souza, 2008. Para el caso de Córdoba, véase Rodríguez,

9 Bubello, 2010. 
Estos estudios se interrogan sobre objetos diversos, desde el grado de efectividad que el ejercicio de la autoridad del Estado tuvo con respecto a las prácticas de medicina no diplomada, popular o curanderismo, hasta la específica forma en que la aparición de los Consejos de Higiene ligada a coyunturas sanitarias y políticas ${ }^{10}$ y la construcción de los curanderos como sus primeros enemigos indica el lugar que la salud pública ocupó en los ciclos de atención del Estado en formación. ${ }^{11}$ Estos interrogantes están vinculados a los procesos de conformación de la profesión médica dotada de legitimidad académica, pero principalmente social a escala local y regional. Así, los médicos «oficiales» fueron logrando que sus propuestas ganaran peso en las políticas públicas, ${ }^{12}$ posición desde la cual abogaron por el cumplimiento de las condiciones que la medicina académica debía reunir. Lo antedicho pone de manifiesto que los estudios existentes sobre curanderos, sanadores y la medicina popular no arrojan — aun — una visión general del tema, como así tampoco de la problemática específica de la tensión entre estos y los médicos. Este trabajo dialoga con dichos aportes, y pretende analizar una de las aristas de la profesionalización médica y la medicalización social, como fueron los numerosos intentos de reprimir y limitar el accionar de sanadores tradicionales.

La conflictividad que signó la relación entre médicos y curanderos se ha constituido en objeto de indagación histórica en los últimos años, ${ }^{13}$ en estudios que - a pesar del carácter fragmentario que presentan - han superado ciertos enfoques que pensaban el «triunfo» de la medicina diplomada atribuyendo un carácter a la vez performativo y efectivo a la letra de las normas que regulaban la praxis médica desde el siglo XVIII. ${ }^{14} \mathrm{Al}-$ gunos casos, por otra parte, resultan ejemplares de una serie de procesos subyacentes a la figuración pública de estos personajes ya avanzado el siglo XX, como el del profesor Carbell de Costa Rica en la década de $1930 .^{15}$

10 González Leandri, 2004. Pascual, 2017. Prieto, 1997.

11 Rodríguez, Carbonetti y Andreatta, 2013.

12 Carbonetti, 1997. González Leandri, 2006.

13 Sowell, 2002. Ferreira, 2003. Armus, 2016.

14 Amodio, 1997.

15 En efecto, Carbell, reunía una serie de saberes que vinculaban el plano espiritual y el médico, y al momento de ser denunciado por la policía de Salubridad presentó su caso no solo con un número importante de testimonios a su favor, sino que realizó un uso estratégico de una miríada de medios escritos (Molina y Palmer, 1996). En su análisis, Palmer muestra que el éxito de Carbell y su persecución por los médicos diplomados era en realidad el espejo de un proceso sobre el eclecticismo médico que se presentaba como una nueva dimensión de la medicina popular, al tiempo que le permitía dar cuenta de un particular proceso de imbricación de los mundos privados y públicos y la política, a la luz del fenómeno que el autor abordó como «populismo médico» (Palmer, 2002). 
La historiografía argentina ha relevado algunos casos significativos, donde el análisis de los sujetos que curaban fuera de la tradición académica se enfocó en el curanderismo o el parterismo, como son los estudios sobre casos de las actuales provincias de Tucumán, ${ }^{16} \mathrm{Jujuy},{ }^{17}$ Córdoba, ${ }^{18}$ Territorios Nacionales ${ }^{19}$ y Buenos Aires. ${ }^{20}$ Una figura vinculada a estos trayectos es la de los «charlatanes» en la cultura científica decimonónica, abordada prolíficamente en una miríada de estudios que se han preocupado por señalar su presencia, destacar las dificultades documentales de su rastreo, y fundamentalmente enfatizar el carácter trasnacionalizado e itinerante de los saberes que componen la ciencia «oficial», dando cuenta así de la mutua imbricación existente entre conocimientos del mundo popular y su recepción y resignificación en el campo de la medicina erudita. ${ }^{21}$ Sin embargo en este artículo no profundizaremos esta rica perspectiva analítica sino que buscaremos analizar los conflictos que se suscitaban entre médicos académicos (que podían ejercer gracias a la reválida de los órganos estatales) y falsos médicos o curanderos.

Va de suyo que el objeto de estos trabajos afronta dificultades documentales, que en buena medida han marcado el ritmo de constitución del sub campo historiográfico de la salud y la enfermedad. Para el caso del tenso vínculo entre una medicina tímidamente oficial y otra de carácter empírico y «popular», las investigaciones comparten limitaciones con el conjunto de los estudios sociales del siglo XIX y pueden pensarse en un doble registro: por una parte, escasez o discontinuidad documental; por otra, el hecho de que la gran mayoría de dichos documentos fueron producidos por elites «estatales». En este último punto, sin embargo, veremos que el ejercicio del derecho de petición a las autoridades por parte de los vecinos no fue una práctica menor, ${ }^{22}$ así como también que las propias fuentes «oficiales» dan cuenta de ciertas lagunas y de situaciones donde el marco legal y administrativo era puesto en segundo plano por parte de los cuadros estatales.

Por otra parte, es preciso señalar que los trabajos existentes reúnen dos condiciones que dan cuenta de su relevancia historiográfica. En primer término, y en tensión con las miradas generales, ponen en relieve los

16 Fabermann, 2005.

17 Fleitas, 2007.

18 Carbonetti, 1997.

19 Di Liscia, 2003.

20 Armus, 2007. Dahhur, 2013.

21 Podgorny, 2012; 2015.

22 Garcilazo, 2014. 
rasgos propios de las regiones estudiadas, un planteamiento que responde a un debate más que saldado en la pesquisa histórica contemporánea que ha revisitado el carácter territorial del enfoque regional para pensarlo como perspectiva teórico-metodológica de trabajo ${ }^{23}$ En segundo lugar, metodológicamente rescatan el estudio del «acontecimiento» como parte constitutiva de la trama social, permitiendo el trazado de una cartografía de lo social bajo una clave más densa. ${ }^{24}$ Este trabajo busca hacerse eco de estas visiones para analizar un fenómeno general bajo la lógica de instancias particulares y discontinuas de lo social en el espacio abordado.

El conjunto de casos empíricos que analizamos en este artículo transcurren en el territorio de la actual provincia de Santa Fe, Argentina, durante la segunda mitad del siglo XIX. ${ }^{25}$ Cabe señalar, en este sentido, que el corpus de fuentes utilizado fue reunido a partir de expedientes administrativos, judiciales y civiles, lo cual nos permite iluminar aspectos del proceso de medicalización en esferas del plano cotidiano entre tantos otros posibles. Una de las mayores potencialidades de los archivos en este período de indefiniciones de la autoridad estatal reside en la cotidianidad que permiten inferir sobre los sujetos involucrados, así como su capacidad de crítica sobre los documentos oficiales elaborados desde las elites y las agencias que ocupaban. ${ }^{26}$

En un contexto de integración del país al sistema capitalista y de sus particularidades geo-climáticas, la provincia de Santa Fe fue una pieza clave en el proyecto productor de materias primas que definió su incorporación. Esto no implicó, empero, un proceso homogéneo para el conjunto del territorio provincial, donde se distinguen tres regiones de ocupación y explotación del suelo, con el arribo de flujos migratorios externos e internos y con las transformaciones sociales consecuentes: el sur pampeano, con una fuerte impronta de grandes propietarios absentistas que encontraron en los negocios inmobiliarios rurales y en el arrendamiento pingües ganancias; la franja transicional central, con el predominio de pequeñas y medianas propiedades abocadas a la producción agrícola o ganadera intensivas; y el

23 Fernández y Dalla Corte, 2001. Fernández, 2007; 2008.

24 Revel, 2005 .

25 Hemos procurado realizar una transcripción literal de las fuentes abordadas, en tanto entendemos que reflejan cambios significativos en el uso de la lengua. Dada la cantidad de diferencias que presenta la escritura y ortografía con el sistema actual, hemos obviado agregar la aclaración luego de cada una de ellas.

26 Otros trabajos han abordado el problema del curanderismo desde fuentes diversas, como la prensa, véase Rivero, Carbonetti y Rodríguez, 2017. 
norte chaqueño, con escaso poblamiento, abundancia de recursos boscosos y pobre fertilidad de los suelos, lo cual orientó su economía hacia la actividad forestal y de extracción de tanino. ${ }^{27}$

\section{El control de las prácticas de curar: un camino espinoso}

A partir de la segunda mitad del siglo XIX, momento en que los actuales territorios provinciales comenzaron a ganar estabilidad administrativa luego de los conflictos post independencia que atravesaron al antiguo virreinato del Río de La Plata, encontramos algunos registros del incipiente problema de la legitimidad de quienes ejercían prácticas de curar. Podemos diferenciar, en este sentido, un primer panorama hacia fines de la sexta década del siglo. En 1861, Teófilo Romang, médico diplomado, fue «recibido» por el Concejo Municipal de la colonia agrícola de Esperanza como médico del pueblo, asignándole el pago de cuatrocientos pesos bolivianos anuales. Como dicha suma nunca le fue abonada por falta de recursos del municipio, el galeno comenzó a cobrar honorarios particulares a los ciudadanos por sus prestaciones. Tres años después de su llegada, empero, vemos el primer registro documentado de la conflictividad entre los médicos diplomados del territorio provincial y los practicantes del arte de curar no académico cuando Romang se dirige al gobernador para denunciar a Felipe Vehr por ejercicio ilegal de la medicina:

Pero hace ya tiempo que el colono Felipe Vehr se ha permitido sin autorización ninguna a curar enfermos y componer algunos miembros quebrados, cuyos he tenido a varias veces que quebrar en segundo para poder componerlos, y también se ha permitido hablar mal de mi persona desacreditándome a los demás colonos, particularmente de mi oficio y arte. ${ }^{28}$

Aquí se juegan dos factores en la denuncia de Romang. Por una parte, el simple hecho de que, ante el cobro por sus prácticas, es más que probable que Vehr no solo haya tenido una presencia más arraigada en el lugar sino que además haya solicitado un pago más modesto, presumiblemente a partir del trueque, como veremos ocurría con otros curanderos. Otro tanto se dirimía desde el plano de la reputación de Romang, quien de esa manera lo

27 Hourcade y Godoy, 1993. Gallo, 2004.

28 Archivo General de la Provincia de Santa Fe (en adelante AGPSF), Ministerio de Gobierno (MG), tomo 25, 1864, exp. 16. 
expresa en su solicitud : «Por esos motivos vengo a solicitar de V.E. dignase ordenar por medio del Sr. Juez de Paz a dicho Felipe Vehr que cesa tales hechos sin que me veré en la obligación de dejar la colonia a la merced de un charlatán según lo dice el Sr. Juez de Paz en su declaración...». ${ }^{29}$

En el mismo año, los vecinos de Coronda enfrentan un cuadro epidémico a partir del cual apelan al gobernador solicitando auxilio. Observemos aquí no solo la escasa disponibilidad de profesionales para actuar en contextos críticos, sino también las concepciones sobre la enfermedad plasmadas en la solicitud:

hace algún tiempo a que este vecindario sufre el flagelo de enfermedades que por su desarrollo estraordinario en el vecindario se deja conocer ser ya de carácter epidémico sin que se haya notado disminución alguna, sin embargo del cambio de estación y de haber llovido algunas veces; motivos suficientes que podrían haber contribuido a su total desaparición pues, que sin embargo de la templanza de la admósfera parece que hoy se presenta de un modo recrudecido manifestándose sucesibamente bajo nuevos síntomas que tienen alarmada a la población. ${ }^{30}$

Ante este cuadro, los diecinueve vecinos que firman la petición solicitan un médico más que colabore con el que ya se encontraba en el poblado:

En tal conflicto ocurrimos a la paternal protección de V.E. para que atendida nuestra demanda, se digne destinarnos un facultativo de Medecina ya sea de los que existen en la Capital o de los del Rosario, en la forma y manera que lo estime conveniente, al fin de que asociado al ciudadano Dn Felipe Fernandez el único con el que actualmente cuenta la población como médico, puedan en cuanto les sea posible contener el desarrollo de dichos males, o buscar algún genero de preservación ${ }^{31}$

Apenas unos años más tarde, en 1867, desde el Departamento de San José y Calchines se dirigen al gobernador apelando a una solución más práctica que el envío de un diplomado: precisamente ante la falta de médico y la presencia de un curandero, solicitan que este último sea habilitado para poder ejercer:

que caresiendo en los referidos Departamentos, de un médico, para atender a los enfermos, pues lo exije ya el cresido número de habitantes, que no vajaron de dos mil quinientos á tres mil, venimos ante V.E. a pedir al Sr. Dn. Visente Bital por ser ya conosido de todos, y haber echo acá varias curas notables, lo que nos prueba los buenos conosimientos prácticos que tiene, y á mas de esto, lo umanitario y desinteresado que

29 Idem.

30 Idem.

31 Idem. 
se á manifestado, por todo lo espuesto esperamos que V.E. accederá a nuestra solicitud, por la escasez que tenemos de médico, y por que en este tenemos confianza. Por tanto a V.E. suplicamos se digne a concedernos esta gracia. ${ }^{32}$

Estos casos presentan un panorama donde es posible observar las primeras iniciativas de la medicina diplomada por disputar un lugar legítimo a los practicantes populares, que, como resulta evidente, contaban con un nivel de inserción comunal y hasta con mayor autoridad que los incipientes practicantes «oficiales». Junto al problema de la legitimidad emergía un segundo aspecto, la escasez de médicos letrados para «competir» con los curanderos, así como los límites concretos del «brazo» del Estado a la hora de asegurar un lugar para estos últimos.

Los reclamos tanto de los vecinos como de los actores médicos, por otro lado, tuvieron eco recién hacia 1868, año bisagra para la profesión en la provincia, al menos en términos institucionales. Motorizados a partir de la epidemia de cólera del año anterior, en dicho año se crearon los Consejos de Higiene de Santa Fe y Rosario, así como la Asistencia Pública de esta última ciudad. ${ }^{33}$ Concebidos para monopolizar la atención de la salud desde el Estado, así como el control de las prácticas de los particulares, entre sus objetivos señalaban el control de títulos y autorización del ejercicio de los ramos menores - como las parteras o flebótomos - y de las farmacias, la visita de establecimientos en los contextos de brotes epidémicos y fundamentalmente el «celar» el ejercicio profesional de los galenos. Considerando la escasez de practicantes diplomados, fue corriente la inserción y autorización de médicos extranjeros, a los que más adelante se les solicitaba un examen de reválida. ${ }^{34}$

Casi veinte años después veremos un funcionamiento distinto en la lógica de las denuncias por parte de los galenos, que si bien contaban ya con un cierto respaldo institucional, su legitimidad aun no lograba decantar en el tejido social. Vemos así que, nuevamente en la localidad de Esperanza, el primero de abril de 1886 un importante número de médicos y farmacéuticos se dirigieron a las autoridades denunciando las dimensiones y el accionar de los curanderos en la zona. De acuerdo con la descripción que realizan, el problema tendría una extensión considerable en tanto afectaba a mayores actores, puesto que no solo realizaban prácticas curativas, sino que además

32 AGPSF, MG, tomo 31, 1867.

33 Prieto, 1996.

34 Registro Oficial Santa Fe, tomo VI, 1867-1869, 240-245. 
sugerirían el consumo de ciertos medicamentos no reconocidos por el Consejo de Higiene —y por ende «ilegales»—, los cuales serían expedidos en comercios que tampoco estaban autorizados por la institución:

\begin{abstract}
Al Sr. Gefe Político del Departamento Las Colonias [...] Los abajo firmantes, Doctores en Medicina y Cirugia, y farmacéutico establecidos en este pueblo, y habilitados legalmente para el ejercicio de nuestra profesión por autorización del tribunal de $\mathrm{Me}$ dicina de la Capital, ante V.E, con el debido respeto nos presentamos y esponemos que: Habiendo tomado el curanderismo grandes proporciones con gran detrimento de la Salud de este pueblo, llegando el atrevimiento de algunos curanderos hasta el punto de usar medicamentos heroicos con daños crecidísimos, y esponer de este modo la vida de los enfermos y existiendo a mas establecimientos que bajo el nombre de Farmacias o Boticas, espenden estos medicamentos peligrosos sin estar debidamente autorizados; y siendo estrictamente prohibido por la Ley, el ejercicio de Medicina o Farmacia en la Provincia a personas no autorizadas, rogamos a V.E. por salvaguardia de la población, y defensa de nuestros derechos legítimamente adquiridos, se sirva hacer citar a las personas que hoy dícense ocupar indebidamente en el ejercicio de la Medicina y Farmacia, y les ordene que inmediatamente obtengan la autorización correspondiente del Tribunal de Medicina de Santa Fe, o cesar en el ejercicio de un ramo que no les corresponde, bajo las formas que la Ley establece. ${ }^{35}$
\end{abstract}

Como podemos ver, ha cambiado la lógica de la argumentación. Por una parte, llama la atención la apelación a un derecho obtenido ya en términos corporativos, donde la actividad profesional se incluye con todos sus matices - práctica médica y farmacia-. Un segundo aspecto tiene que ver con la apelación al riesgo de dichos servicios y productos sobre la población como motivaciones de su requerimiento. Por último, y no menos importante, esta denuncia revela el hecho de que, junto con ciertas prestaciones no oficiales que era preciso detener para resguardar el saber y el campo laboral de los especialistas, se abría la necesidad de regular y resguardar el consumo de aquellas sustancias que la medicina delimitaba como efectivas en términos terapéuticos. Esto es, no solo el acceso a la «salud» vendría de la mano del médico autorizado, sino también el consumo de aquellas sustancias que la cultura «popular» local utilizaba como apoyos al proceso curativo.

Ante la solicitud de los miembros locales de la corporación, el jefe político solicitó asesoramiento al gobierno de la provincia, donde le indicaron «convocar a un despacho a todos los médicos (o que pasen por tales) y Farmacéuticos y exigirles un correspondiente diploma o permiso del tribunal

35 AGPSF, MG, tomo 88, 1887, exp. 22. 
de medicina de esta capital. Los que no lo exhibieren deben sufrir la multa legal y su respectivo apercibimiento». Ahora bien, al tomar conocimiento de la cuestión, el Consejo de Higiene interpuso su visión del asunto, que expresaba, por una parte, su voluntad de ganar mayor peso como instancia regulatoria y, por otra, su voluntad de contar con la colaboración tanto de funcionarios políticos como de los cuadros de seguridad para ejercer el control de las prácticas de curar. Este último punto será, como veremos, uno de los mayores obstáculos con que contarían, dada la inscripción local de los colaboradores requeridos.

Sr. Ministro: Siendo justísima la solicitud de los Médicos y Farmacéuticos de la Esperanza, el Consejo de Higiene cree que debe pasarse no al Gefe Político de esa ciudad para que ponga en conocimiento de los que ejercen la profesión de Médicos o Farmacéuticos, sin ser recibidos en alguna de las Facultades de la república que se presenten a este Consejo entes del término de un mes renovar la autorización si la tienen o solicitarla para el futuro. Los abusos cometidos por curanderos y boticarios son sin cuenta, por lo que si V.E., como este Consejo, considera de necesidad cortar de raíz los medios que a ciertas personas sirven para explotar la ignorancia del pueblo y a fin de garantir en lo posible la salud del pobre facilmente engañado, convendría oficiar a las autoridades de los Departamentos San José, San Javier, Las Colonias y San Gerónimo que corresponden a la jurisdicción del Consejo de Higiene de la Capital en igual sentido que al de la Colonia Esperanza, así como que no concedan patente de médico y Farmacéutico a los que no presenten diploma o autorización de este Consejo; de esta manera estado prevenidos pueden hacerse efectivas las multas. Es cuanto tiene que informar este consejo de Higiene al Sr. Ministro. Candido Pujato. ${ }^{36}$

Esta actitud por parte del presidente del Consejo pone en evidencia algunas cuestiones. Si bien por una parte traduce una serie de cambios que habían cristalizado en la nueva estructura que adoptó el Consejo de Higiene a partir de su reforma en 1887, por otra parte da cuenta de la competencia que estos sanadores empíricos representaban para las prácticas «oficiales», y de allí la necesidad de contener y reprimir dichas prácticas. En términos de su estructura, el Consejo centralizó sus actividades en la capital provincial, subordinando la sede existente en la ciudad de Rosario a este último. Además, luego de casi dos décadas de funcionamiento, el organismo redefinía sus funciones respecto a la corporación médica así como su posición en y para el Estado. Si, por un lado, reforzaba su potestad de autorización de títulos extranjeros, el avalúo de honorarios médicos, su lugar en la aplicación de penas por ejercicios irregulares — donde se incluía la mediación

36 Idem. 
y legitimación de las mismas por parte de un abogado y un juez del crimen-, o su control sobre las condiciones edilicias higiénicas en farmacias y la puesta en uso de la farmacopea francesa, por otro lado hay indicios que muestran su orientación como una agencia y un saber orientados hacia el Estado. Además de que sus miembros ahora eran designados por el poder ejecutivo y tanto estos como los inspectores percibían una remuneración, entre sus nuevos objetivos el Consejo se propone elaborar una estadística médica, brindar asesoramiento a municipios y comisiones de fomento, la posibilidad de nombrar comisiones higiénicas cuando sean requeridas, la imposición a los diplomados de informar cualquier indicio de brote epidémico y un refuerzo sobre sus actividades de inspección de establecimientos médicos y especialmente farmacéuticos. ${ }^{37}$

\section{¿Curanderos o médicos ilegales? Disputas sobre el monopolio de curar}

Estos cambios marcan una nueva actitud respecto al control y persecución de las prácticas «ilegales» de ejercicio de la medicina, y el caso que inaugura este período del Consejo de Higiene lleva una doble particularidad. Por un lado, por el tenor de la denuncia - llevada a los límites del paroxismo-; por otro, por ser el primer caso donde, ante las sucesivas misivas y multas aplicadas por el Consejo, el curandero acusado responde con una denuncia contra su presidente, en la cual un asesor letrado expuso una serie de argumentos legales para legitimar su derecho a ejercer una práctica. ${ }^{38}$ Se trata de Juan Pablo Quinteros, quien no era curandero sino espiritista, y cuyo caso ha sido objeto de otros trabajos. ${ }^{39}$

Años más tarde, el 9 de octubre de 1894 Guillermo Ovalle, médico de policía de Helvecia — localidad del norte provincial—, se dirige al ministro de Gobierno provincial para denunciar ciertas irregularidades que no atañen ya solo a la prestación de servicios por parte de los «sanadores» locales, sino también a la necesidad de controlar ciertas prácticas que se buscaba secularizar y ubicar bajo la órbita del Estado, como el registro de defunciones:

37 Registro Oficial Santa Fe, 1887, 159-167.

38 «Atanacio Páez en representación de Juan P. Quinteros contra el Consejo de Higiene», AGPSF, MG, tomo 115, 1887, exp. 30. «Vecinos solicitan se autorice a Juan P. Quinteros», AGPSF, MG, tomo 88, 1887, exp. 22, n. ${ }^{\circ} 6489$.

39 Sedrán, Carbonetti y Allevi, en prensa. 
Al objeto de evitar aquellos y poner trabas á un sin número de curanderos que egercen la medicina sin titulo ni permiso alguno, solicito de SS. disponga (salvo su mejor parecer) que esta Comision de Fomentos no consienta en el enterramiento de ningun cadáver sin certificación del reconocimiento facultativo, pudiendo saberse asi las enfermedades que predominan en el pueblo, el caracter que revistan y, en casos epidémicos tomar el Médico de Policia que suscribe de acuerdo con el H. Consejo de Higiene todas aquellas medidas que la Ciencia y la Higiene establecen. Por otra parte, y siguiendo marcha tan anómala como hasta hoy se sigue pueden cometerse crímenes dejando vurlada la acción judicial; en su virtud y atendiendo a lo que dejo consignado, vengo a pedir a SS. lo solisitado si lo cree en justicia... ${ }^{40}$

Apenas unos meses después, se desató una misiva interesante en la localidad de Sunchales por el contexto donde se desplegó así como por el accionar del Consejo, donde Manuel Martínez Olano fue acusado por ejercicio ilegal de la medicina. El 12 de diciembre de 1894 el presidente del organismo solicitó al juez de paz de la localidad que gestionase el cobro de una multa al sujeto en cuestión por ejercer la medicina de forma ilegal, habiendo sido apercibido previamente:

Comprobándose nuevamente que el Sr. Martinez Olano ejerce la medicina, no obstante prohibicion anterior, se ha resuelto aplicarle una multa de doscisntos pesos moneda nac., cantidad que hará usted efectiva trabando embargo de sus bienes en caso se niegue a satisfacerla. El resultado de sus diligencias se servirá hacermelo conocer por primer correo. ${ }^{41}$

Dos días después, el magistrado informa sobre la recepción de la solicitud y del procedimiento efectuado. Es importante que retengamos el devenir de los acontecimientos aquí. Cuando informan a Martínez Olano de la multa, este alega no tener medios para abonarla, lo cual es ratificado por dos testigos, y con ello se da por finalizado el asunto:

En la misma fecha me constituí al domicilio del Sr. Martinez Olano, a quien notifique de la precedente resolución del honorable Consejo, intimándole el pago de la multa establecida, y habiéndose negado a pagarla, le requerí bienes a embargo; a lo cual tambien contestó que no tenía ningunos. Resultando de las diligencias practicadas que no posee otros bienes que los muebles de su preciso uso, se dio por terminado este acto que lo firmó el notificado y los testigos suscritos por ante mi de quien certifico. ${ }^{42}$

40 «Guillermo Ovalle se presenta en queja contra los curanderos de Helvecia», AGPSF, MG, tomo 320,1894 , exp. 42.

41 AGPSF, MG, tomo 30, 1895, exp. 30

42 Idem. 
El resultado de la requisitoria, firmada por Martínez Olano, dos testigos y el juez de paz involucrado, no satisfizo al presidente del Consejo, quien apenas unos días después recurrió a la autoridad jerárquica superior al juez de paz, esto es, el jefe político del departamento de Rafaela, para que comprobara si las diligencias fueron certeras o no:

Por segunda vez el Consejo se sirve solicitar su concurso para hacer efectivas las medidas tomadas contra del curandero Sr. Manuel Martínez Olano. Hoy se trata de saber si las diligencias hechas por el Juez de Paz de Sunchalez son exactas. Sírvase ordenar las averiguaciones necesarias, y si resultaran falsas, disponer se efectue la multa de \$200.- por los medios que el Jefe Político estime más rápidos y seguros. Saludalo atentamente. Candido Pujato. ${ }^{43}$

En medio de esta nueva solicitud de Pujato, acontece algo que evidencia la incongruencia entre la pretendida legitimidad que este reclamaba para la corporación médica y la legitimidad y peso local de las figuras asociadas a la prestación de servicios de salud en las comunidades. El 30 de diciembre de 1894, el comisario general del poblado se dirige en un telegrama al ministro de Gobierno - por encima del Consejo de Higiene - notificando sobre un brote epidémico de cólera ante el cual, por falta de médico, propone se habilite a este sujeto que ya contaba con la negativa del órgano de la corporación:

Sr. Ministro de Gobierno de S. Fe. Oficial. Participo a SS. que esta población está alarmada con la epidemia del cólera y la falta de médico por haberse ausentado el que había aquí esta el Dr Manuel Martinez Olano pero como consejo de higiene ha ordenado que no cure. Digame si SS. le podrá permitir en vista de las circunstancias por que atraviesa esta población. Saludo a SS. ${ }^{44}$

La tensión que las medidas del Consejo despertaban al evidenciar su fragilidad institucional y la escasa cobertura que alcanzaba en contextos normales se agudizaba en tiempos de crisis. Esta carencia de legitimidad explica esta apelación a una figura jerárquica del Estado provincial respecto al Consejo, y no se resumía solo en el pedido del comisario, sino que un grupo de vecinos también dirigió su telegrama al ministro de Gobierno, donde alertaban por la salubridad de la población y reclamaban la autorización de Martínez Olano en dicho contexto:

43 Idem.

44 AGPSF, MG, tomo 30, 1895, exp. 12. 
En motivo del flagelo que nos amenaza por el contacto en que estamos con Rosas y esa capital y habiendose retirado para Cordoba el Sr. Carlos Achaval pedimos a SS. ponga en conosimiento del Sr. gobernador que encuentrase aquí el Sr. Martinez Olano, medico extranjero que esta inhibido por el Consejo de Higiene a ejercer su profesión. Por las circunstancias espuestas pedimos a SS. y al Sr. Gobernador la autorización [...] para que este Sr. pueda ejercer la medicina y poder a la vez tomar medidas preventivas contra la epidemia reinante. Esperamos se nos atienda urgente. Saludamos al Sr. Ministro. Adolfo K. Gielz, I. Maistany, Antonio I Rodriguez, Choistensen y Cia, Koennig y Cia, Angel Bagliente, I del Casto. ${ }^{45}$

Seis días después, el Ministerio de Gobierno pasa la nota al Consejo para su evaluación, que se expide en pocos días negando la posibilidad de autorizar a Martínez Olano y enfatizando su carácter «ilegal» no solo desde su práctica, sino también por no haber abonado las multas impuestas. La lectura sesgada que realizaban respecto a la normativa y a las posibilidades mismas de reunir las condiciones para llevarlas a cabo es evidente:

Los artículos del Reglamento prohiben terminantemente se faculte al ejercicio de la medicina a personas que carezcan de títulos universitarios. Por esta causa se prohibió al Sr. Martinez Olano ejerciera el arte de curar hasta tanto no presentara documentos que comprobasen su competencia. No lo hizo, persistiendo por varias ocasiones, por lo que se le aplicaron dos multas; una de $\$ 100$.-, satisfecha, y la otra de $\$ 200$.- impaga aún, y cuya efectividad se ha recomendado al Gefe Político de Rafaela, por no haberlo hecho el Juez de Paz de Sunchalez. El Consejo no podria permitir se facultara al Sr. Martinez Olano, como o solicitan, por las razones expuestas, y porque será abandonar la suerte de aquellos habitantes en manos de un particular, lo que significa acarrearse la responsabilidad de los actos de aquel. Por otra parte, si el mal llegara a amenazar a Sunchalez, se aconsejaría inmediatamente el envío de un facultativo. Por hoy, esta Corporación no tiene a quien indicar se le proponga la plaza dejada por el Dr. Achaval. Candido Pujato. ${ }^{46}$

Sucede entonces que tras esta petición de la comunidad por la habilitación de Martínez Olano y la reiterada negativa de Pujato, el 7 de febrero de 1895 el jefe político de Rafaela respondió al recurso administrativo presentado por el presidente del Consejo el 20 de diciembre del año anterior, donde informaba que no fue posible darle curso, dado que «el Sr. Martinez Olano se ha aucentado de "sunchales", ignorando su domicilio». ${ }^{47}$ Esta respuesta no logró otro resultado que exacerbar aun más al presidente del

45 Idem.

46 Idem.

47 «Presidente del Consejo de Higiene acompaña notas quejándose de la demora de algunas autoridades para los asuntos de dicho Consejo», AGPSF, MG, tomo 30, 1895, exp. 30. 
Consejo, quien se dirigió con el asunto al ministro de Gobierno, apuntando contra el accionar del funcionario de Rafaela, a quien acusaba de obrar deliberadamente en contra de las disposiciones requeridas, y en favor del curandero:

Para que su SS pueda darse cuenta del retardo notable con que proceden las autoridades de campaña en asuntos de suma importancia, que este Consejo recomienda, me permito acompañar la nota $\mathrm{n}^{\circ} 890$ en la que se solicitaba averiguaran la veracidad de lo expresado en la nota 877. Sírvase fijarse SS en la fecha de la diligencia, en la forma en que se hace, en el poco interés que se demuestra, y tendrá forzosamente, que convenir que la buena voluntad de esta Corporación se verá siempre quebrantada por la decidia, cuando no por la mala intención de empleados sin escrúpulos. ${ }^{48}$

Esta última requisitoria no fue bien recibida por el jefe político de Rafaela, que en su respuesta agrega un dato hasta entonces ausente: él era nuevo en el cargo, habiendo asumido a solo veinte días de presentado el recurso de Pujato. Con lo cual, en términos administrativos, había dado cumplimiento a los procedimientos correspondientes.

\begin{abstract}
Al hacerme cargo de esta jefatura, el 14 de enero ppdo. Dediqué los primeros días a examinar los expedientes atrasados entre los que se hallaba el presente del Consejo de Higiene que se remitió a esta Jefatura el 20 de diciembre último; procuré indagar cuál fuera el paradero del Sr. Martinez Olano y como supe que no se hallaba en Sunchales ni cual era su residencia se lo hice notar en el citado expediente al Señor Presidente con fecha 7 del actual pues nada podía hacer. Por tanto creo que no es pertinente la falta que en la nota 14 del actual me atribuye el Señor Presidente del referido Consejo, puesto que desde el 20 de diciembre fecha de la nota hasta últimos de enero en que yo me enteré del asunto no es culpa mía que no se tramitara; y la prueva de mi celo en pro de este asunto es palpable, pues a los 7 días ya lo devolví informado diciendo que ignoraba el paradero del Sr. Martinez y no hallándose en mi Departamento mal podría dar cumplimiento a lo que se solicitaba. ${ }^{49}$
\end{abstract}

Con esta respuesta, es posible analizar el caso de manera inversa a lo que las fuentes plantean inicialmente. Si en un principio es evidente que los policías y funcionarios locales estaban protegiendo a Martínez Olano al afirmar que no era posible dar con su paradero, la intervención del nuevo jefe político muestra que la imposibilidad de llevar a cabo la voluntad del Consejo respondía, en verdad, a situaciones estrictamente contingentes. Es menester, empero, que retengamos la actitud de Pujato. A pesar de que hemos reconocido una particular predisposición en la actitud de este

48 Idem.

49 Idem. 
personaje al analizar el caso del espiritista Juan Quinteros, sus sospechas sobre las trabas que la comunidad y los agentes del Estado a nivel local podían estar interponiendo en su requisitoria contra Martínez Olano nos da el indicio de que ese escenario era más que posible y esperable. El hecho mismo de que los funcionarios encargados del ejercicio de la violencia legítima no llevasen a cabo las instrucciones del Consejo evidencia que, a pesar de su incremento de atribuciones y su voluntad reguladora, estos intentos no encontraban un correlato en el tejido social, después de casi treinta años de funcionamiento.

El caso que sigue también da cuenta de una nueva forma de canalización de los conflictos por parte del Consejo, y un recrudecimiento de los controles y de los mecanismos administrativos para lidiar con quienes ejercían el arte de curar sin autorización. En 1901 José Lardone, médico cirujano, se dirige al ministro de Gobierno para denunciar el accionar de un supuesto médico alemán, Teofilo Kuntz, que competiría con él en la prestación de servicios, ejerciendo la medicina sin estar autorizado por el Consejo. A diferencia de los casos que hemos revisado, aquí el médico «oficial» alega haber sido consultado en casos donde el galeno germano había intervenido y cobrado honorarios, que detalla con nombre y apellido en su nota:

\begin{abstract}
Hace un año más o menos se ha establecido en el pueblo de Armstrong de este Departamento, un señor cuyo apellido es Teofilo Kuntz, de nacionalidad alemana, el cual ejerce la medicina sin autorización del Consejo de Higiene. El que suscribe ha sido llamado varias veces para asistir enfermos en dicha localidad, los cuales habían ya sido visitados por dicho Sr., a quienes había recetado y cobrado sus honorarios. Este señor se presenta como médico y según referencia, ha practicado una autopsia. Como este señor ha sido apercibido por el anterior Consejo de Higiene, así reitera la denuncia para los proveimientos necesarios. Confiando en que SS. hará respetar los intereses y el decoro que merece el arte de curar..$^{50}$
\end{abstract}

El avance del procedimiento administrativo implicó al jefe político del departamento San Martín, quien fue compelido a comprobar la veracidad de la denuncia de acuerdo con las disposiciones vigentes, y por ello deriva el asunto al juez de paz de la localidad de Sastre para que inicie un proceso administrativo. Aquí veremos la novedad de este caso: se convoca a los sujetos mencionados en la denuncia de Lardone y se les toma declaración. El mismo día que dicho juez de paz recibe la solicitud, comienza el proceso

50 AGPSF, MG, tomo 356, 1901. 
y toma declaración a un testigo, agricultor e italiano, de cuarenta y cinco años, que dice conocer a Kuntz - a quien «corresponden las generales de la ley»- pero ignora la razón por la que se lo convoca. Cuando el juez pregunta si el curandero utilizó su casa para atender y recetar, el testigo responde que cuatro meses atrás su esposa enfermó y recurrió a Kuntz pidiéndole algunos medicamentos, y este cobró una pequeña suma de dinero por su consulta y prescripción. El interrogatorio cierra con una pregunta sobre si Kuntz continúa atendiendo personas en su vivienda y si conoce de otras curas que haya realizado, a lo cual el campesino responde que no ocupó nuevamente sus servicios y que desconoce de otras atenciones. Un segundo testigo fue Juan Gabatto, también agricultor e italiano, de cuarenta y seis años, e ignorante del motivo por el que se lo convoca. Si bien dice conocer a Kuntz, en este caso afirma que «no le corresponden las generales de la ley», y respecto a los servicios que le prestó, declara que ocho meses atrás su padre estuvo enfermo, ante lo cual el sanador recetó un medicamento en forma de inyecciones, desconociendo si las mismas provenían de una farmacia, y como pago le ofreció un regalo, dado que Kunz no puso precio a su trabajo. El tercer testigo convocado, Pedro Pumero, era considerablemente más joven — veintiún años—, y como los dos anteriores, agricultor e italiano, aunque soltero. Como el caso anterior, afirma que al curandero extranjero no le corresponden las generales de la ley, y que su contacto con él fue por una enfermedad de su madre, ante lo cual no recuerda si Kuntz prescribió un medicamento, pero sí que sugirió aplicar hielo en la cabeza. Por dichos servicios Kuntz percibió dos pesos moneda nacional, y al preguntar si conocía otras personas a las cuales Kutnz había prestado servicios, el testigo dice desconocer, pero había atendido a una hermana suya que falleció.

Dos de los sujetos mencionados en la requisitoria de Lardone no residían en dicho poblado, sino en la Colonia de Carlos Pellegrini, con lo cual se solicita y faculta al juez de paz de la misma para ordenar comparezcan ante él a prestar indagatoria. El primero en hacerlo es un agricultor llamado José Mondino, italiano de veintidós años, quien dice conocer a Kuntz por haber enfermado dos meses atrás, ante lo cual se lo convoca. El sanador hizo dos visitas y cobró por sus servicios dos pesos, desconociendo el testigo si realizó otras curaciones. La segunda testigo es Ángela Rinaudi de Perrotti, italiana de cincuenta y tres años, casada —único caso donde se aclara que lee y escribe- y con seis años de residencia en el país. Esta mujer dedicada a los «quehaceres domésticos» afirma que solicitó los servicios de Kuntz a comienzos del año, quien hizo una sola visita y cobró tres pesos. 
Una vez finalizadas las indagatorias requeridas, se remiten las doce fojas al Ministerio de Gobierno, donde se deriva el expediente a la Inspección de Policía, que resuelve que Kuntz ejerce la medicina y cobra honorarios, ante lo cual resta saber si estaba autorizado por el Consejo de Higiene Nacional o bien por el de Rosario o Santa Fe, para determinar finalmente si era preciso o no aplicar penas. Tras dos meses, el Ministerio de Gobierno cierra el caso el veinticuatro de agosto alegando que se desestima la solicitud que cuestionaban las actuaciones de Teófilo Kuntz una vez que este solicitó autorización para ejercer su profesión, la cual aparentemente fue aprobada. Este caso nos muestra el cambio en las prácticas de control del Consejo, que comenzaba a articular sus procedimientos con otras instancias burocráticas del Estado y, con ello, a limitar una de las aristas que permitían a los sanadores populares continuar con sus actividades. Si bien podemos ver en los testigos que continuarían recurriendo a los servicios del curandero, los cuadros estatales comenzaron a desarrollar procesos administrativos reglados, a partir de los cuales la aplicación de las multas y las prohibiciones sobre estos sujetos se tornaba cada vez más severa.

En ese mismo año, Walter Sevilla, médico de policía en San Cristóbal se dirige al ministro de Gobierno en «su lucha contra la audacia de los curanderos» para solicitar que no se autorice a Francisco Beltramino a ejercer la profesión, por no haber defendido su tesis, o bien se lo reubique para que no perjudique a los diplomados. ${ }^{51} \mathrm{Su}$ denuncia incluía, además, un pedido para que sus recetas no se despachen en las farmacias locales, lo cual demuestra que el problema no se circunscribía solamente al accionar del sanador, sino también a la connivencia de sus prácticas con los otros actores locales que participaban de las prestaciones de salud. Si bien cuando se redireccionó su petición al Consejo este reconoció la justicia de su reclamo, al mismo tiempo habilitó a Beltramino para ejercer en alguna zona donde no intervenga ni compita con los «oficiales». Este dato es significativo, en tanto reconoce una excepción a la prohibición que regía sobre los médicos extranjeros y los idóneos desde la reforma del Consejo en 1887, siempre que se resguardase la prioridad del diplomado oficial e inscripto, despejando así su posible competencia.

$\mathrm{Al}$ año siguiente, se registraron dos denuncias contra practicantes ilegales de la medicina que ponen en evidencia las tensiones surgidas no solo entre practicantes diplomados y populares, sino también entre los prime-

51 AGPSF, MG, tomo 358, 1901, exp. 7. 
ros y las instituciones que debían velar por ellos, sea el Consejo, sean las autoridades locales. La primera de ellas se originó en Sunchales, donde ya observamos casos similares, y corresponde al doctor Miguel Alarcón, quien instruye «diligencias sumarias» contra Miguel Piccone por ejercer el arte de curar sin autorización. Uno de los aspectos relevantes del caso reside en que el motor de su denuncia no apuntaba a censurar su ejercicio. Piccone, de nacionalidad italiana pero sin reválida oficial del Consejo de Higiene local, aparentemente difamaba a Alarcón e incumplía las notificaciones recibidas en este sentido por contar, de acuerdo al denunciante, con la «protección» de las autoridades locales. ${ }^{52}$

El segundo caso, acaecido a fines de mayo de ese año, fue recogido por el juez de paz de la localidad de San Genaro, donde el médico local denunció a Francisco Aresse, un sujeto que ejercía el arte de curar de manera ilegal, disputando su clientela, y con una considerable legitimidad social:

Desde hace cinco meses a esta parte que el médico de la localidad Dn Nicolas de Feo, viene quejándose con insistencia contra un curandero llamado Francisco Aresse, que usurpándole su arte ejerce también la medicina clandestinamente, en perjuicio no solo del médico de Feo con título de facultad extranjera revalidado en el país, si que también haciendo víctimas a los humildes o ignorantes habitantes de este pueblo, a quienes induce a creer que la aplicación de su arte tiene la virtud de la «panacea»..$^{33}$

El problema de fondo en este caso fue que el Consejo mismo no daba respuesta a los requerimientos del profesional diplomado, por encontrarse en recambio de autoridades, y por ende temporalmente acéfalo. Esto motiva su apelación a otra instancia burocrática del Estado para canalizar su demanda de reconocimiento y limitar la práctica de Aresse. En su petición, además de bregar por el reconocimiento de su experticia en comparación al curandero, apelaba al bienestar de la población y a los «abusos» que el accionar de este tipo de sujetos representaba sobre la población local:

Como se trataba de funciones que incumbían exclusivamente atender al Consejo de Higiene de esa capital por repetidas veces se insinuó al médico de Feo que recurriera a dicha corporación, resultando que por la acefalía en que ella se encontraba esos reclamos no le han sido atendidos. Ahora bien, como la libertad con que dicho curandero ejerce el arte de curar raya en el abuso en perjuicio de intereses no ya particulares del médico de Feo sino en lo que son más caros, en los intereses de vidas de los vecinos

52 AGPSF, MG, tomo 375, 1902, exp. 16.

53 AGPSF, MG, tomo 376, 1902, exp. 46. 
que aún creen en la eficacia del arte de estos adivinos; y es por ello que llevo este hecho a conocimiento de SS. el Sr. Ministro, pidendole quiera dignarse ilustrarme en el proceder que debe adoptarse para reprimir el abuso denunciado. ${ }^{54}$

El caso fue trasmitido del Ministerio de Gobierno al Consejo, el cual informó que no poseía constancia de haber prohibido a Aresse ejercer su oficio, pero que en todo caso, la notificación del juez de paz sobre su reincidencia será suficiente para aplicar la multa correspondiente. Para ello, además, el órgano corporativo habilitó al magistrado para notificar al sanador que de continuar con su práctica se implementaría el artículo trece del reglamento, por el cual se lo multaría de manera creciente de acuerdo al número de reincidencias. Estos procedimientos significaron, aparentemente, el final del caso, y entendemos que evidencian una nueva lógica respecto a los observados previamente. Si bien el Consejo no fue la entidad que respondió originalmente al reclamo de uno de sus miembros corporativos, fue la autoridad local —representada en el juez de pazquien tomó a su cargo la defensa del médico que proclamaba vulnerados sus derechos. Esto representa una clara diferencia con lo acontecido durante el último tercio del siglo, donde los galenos avanzaban en soledad contra sus «adversarios» en la prestación de servicios de salud, y respondía, en primer lugar, a que los incipientes cuadros estatales no se habían autonomizado en el ejercicio de su función, y luego fueron - lentamente- incorporando nuevas atribuciones. Pero también, en segundo término, podemos agregar que, en su profesionalización, estos cargos de autoridad civil comenzaban a ser desempeñados por personajes letrados que podían empatizar más fácilmente con un profesional diplomado del arte de curar frente a otro «ilegal».

\section{Reflexiones finales}

En este trabajo hemos procurado aportar a dos problemas que atañen al campo de la historia social de la salud y la enfermedad. Por una parte, a los «avatares» del proceso de medicalización social en una provincia de $\mathrm{Ar}$ gentina; por otra, a las derivas de la profesionalización y legitimación médica a partir de una serie de casos que ponen en tensión la supuesta linealidad

54 Idem. 
que las historias tradicionales de la medicina han atribuido al accionar de los médicos y su recepción «positiva» por parte de la sociedad. En efecto, si algo evidencian las fuentes analizadas es, por una parte, la escasa legitimidad con que contaban los galenos y su saber académico, mucho más patente en sectores «rurales» o ajenos a la vida citadina, donde no se encuentran denuncias documentadas. Ahora bien, por otra parte, tanto las solicitudes de los vecinos como las presentaciones de los diplomados dan cuenta de la sinuosidad y conflictividad que signó la profesionalización de la medicina en términos empíricos. Es importante reconsiderar en este proceso la esfera de la «estatalidad», en especial a partir de su no acompañamiento inicial al reclamo de los galenos. Si bien las agencias y el funcionariado estatal se caracterizaron durante el siglo XIX y principios del XX por su condición incipiente, frágil y de fronteras lábiles entre los intereses privados y públicos, los casos abordados muestran cómo, a pesar de inscribir sus reclamos y su agenda en la estructura estatal provincial, esto no aseguraba a los médicos el cumplimiento de sus disposiciones en el entramado territorial, donde su legitimidad era más bien escasa.

Cobra una dimensión especialmente significativa en este artículo el abordaje de estos procesos a la luz de denuncias canalizadas a través de distintas instancias del Estado en varios sentidos. Por un lado, por el trabajo de reunión y sistematización de las mismas en el marco de un conjunto más extenso de fuentes referidas al Consejo de Higiene, pero también y más importante aun, por la localización y rescate de los conflictos entre diplomados y sanadores populares con anterioridad a la existencia de tal institución.

Por otro lado, estas fuentes en su conjunto ponen de manifiesto un aspecto central y previo a cualquier análisis, esto es, la emergencia misma del conflicto entre prácticas de curar, y la progresiva delimitación de un campo de polaridad donde un saber y una terapéutica específicos se erigían como legítimos frente a otro que era preciso desacreditar. En dicha tarea, se apelaba a un tímido criterio de cientificidad frente a la ignorancia de los curanderos, donde vemos configurarse un paradigma propio de la modernidad occidental donde el saber científico se propone como única instancia de saber autorizada, y con capacidad de anulación de cualquier otra. Frente a la constatación inicial de los médicos de que la apelación a la «charlatanería» no resultaba efectiva en su cruzada, la manera más usual de desacreditar a sus oponentes fue, por un lado, insistir en el riesgo al que sometían a la población que a ellos recurría. Pero también, por otro, un aspecto presente en 
la casi totalidad de las denuncias pasa por la difamación de los diplomados; y no es preciso insistir en el hecho de que, en estas sociedades históricas, la apelación al honor y a su respeto era un argumento más audible para las autoridades.

De todo esto rescatamos que, por encima de los intentos de los diplomados, no solo es la legitimidad de su figura como expertos de la salud lo que las fuentes nos informan, sino también la de los saberes que los erigían como tales. Con ello, es posible apreciar la historicidad de la medicina como conjunto de saberes válidos e incuestionables en la promoción de procesos de salud, así como de la medicalización social como proceso unilateral y totalizante.

En un primer momento, entonces, observamos la dinámica de las denuncias de los diplomados y las solicitudes «populares» ante epidemias en un contexto previo a la reglamentación e institucionalización - formalde la corporación bajo la figura del Consejo de Higiene. Los casos contemplados hasta 1868 nos permiten ver los escasos recursos de los diplomados en términos de su posición en el Estado, sea por su lugar casi inexistente — recordemos que Teófilo Romang era médico del municipio de Esperanza pero no cobró su sueldo por años-, o bien por la ausencia de un espacio de defensa corporativa en su interior. Asimismo, las solicitudes de los vecinos muestran no solo la deficiente estructura con que el incipientemente estabilizado Estado provincial contaba ante los brotes epidémicos, sino también la presencia misma de figuras arraigadas en la comunidad que desarrollaban el arte de curar previo a la intervención de estatal.

En un segundo momento del análisis, observamos que las quejas contra los practicantes ilegales comenzaban a ser abordadas directamente por el Consejo de Higiene - a partir de la mediación del Ministerio de Gobierno-, involucrando, además, a los farmacéuticos como miembros de una esfera común regulada por el órgano, el cual dejaba ver su voluntad de reconocimiento como instancia de contralor en lo referido a las temáticas de su incumbencia. Ahora bien, este reconocimiento de los intereses particulares de los galenos como interés común del conjunto por parte del Estado no dejaba de ser estrictamente formal. Los casos que analizamos en la segunda sección del artículo dan cuenta de la inexistente articulación entre dichos intereses y la dinámica de cada poblado.

En la denuncia al curandero Martínez Olano de 1894, emergen con claridad estas tensiones: por una parte, la (escasa) legitimidad local de los médicos en el pueblo donde se desata la misiva contra el sanador. En 
segundo lugar, la «flexibilidad» de las estructuras administrativas y represivas estatales a la hora de llevar a cabo la multa dispuesta por el Consejo, lo cual evidencia algún tipo de connivencia o al menos aprobación de la comunidad de su tarea. Por último, las encendidas respuestas del presidente del Consejo expresan un grado de tensión considerable respecto al incumplimiento de la normativa referida al resguardo de la corporación, que llevaba casi tres décadas de funcionamiento.

Los casos abordados en la segunda sección del artículo muestran particularidades del proceso en otra clave. Por un lado, que las denuncias efectuadas por los médicos apuntaban a sujetos que no eran curanderos sino más bien médicos no autorizados por algún motivo ante el Consejo provincial, y aquí se hace presente un aspecto que atraviesa a todos los expedientes trabajados. No es solo una cuestión de legitimidad lo que preocupa a los diplomados, sino también de competencia en la práctica. Mientras que en un primer momento las denuncias se focalizan en el ejercicio del arte de curar por sujetos «no capacitados» aunque con mayor legitimidad, con el paso de las décadas el foco se desplaza a aquellos médicos que amenazaban el monopolio local de aquellos sujetos que habían logrado la autorización estatal. Con ello, el visto bueno de la corporación institucionalizada pasó a jugar un rol de árbitro de la competencia interna al interior de la medicina oficial.

Por otra parte, el final del siglo XIX evidencia cambios significativos en los procedimientos administrativos del Estado - con el desarrollo de las indagatorias y su uso como prueba-, así como una mayor «predisposición» de los funcionarios de turno para ceñirse a los mismos. No es menor considerar que el componente letrado al interior de la burocracia estatal debía ser más considerable, y con ello su cercanía y «creencia» en la medicina en tanto saber académico legitimado institucionalmente. Entendemos que ello aun no implica un reconocimiento pleno por parte del Estado, sino más bien un cambio en la composición de sus elites y su funcionariado, que podía facilitar el devenir de los pedidos de la corporación.

Es claro que el número de denuncias y solicitudes trabajadas aquí no permite arrojar conclusiones definitivas sobre procesos tan complejos y con múltiples aristas, como fueron la medicalización social, la profesionalización de la medicina y, en particular, la legitimidad del médico como agente primordial y hegemónico de la salud. Entendemos, sin embargo, que en su variedad y extensión temporal permiten vislumbrar la conflictividad y, sobre todo, los denodados esfuerzos que conllevó a la comunidad médica 
diplomada su reconocimiento como un actor de referencia en la búsqueda del restablecimiento de un estado de «salud», un camino en el cual la extensión del saber médico sobre la regulación de la vida de las poblaciones no necesariamente fue exitosa, sino más bien conflictiva.

Recibido el 23 de enero de 2017 Segunda versión el 4 de agosto de 2017 Aceptado el 5 de septiembre de 2017

\section{Referencias bibliográficas}

Amodio, Emanuele, «Curanderos y médicos ilustrados. La creación del Protomedicato en Venezuela a finales del siglo XVIII», Asclepio. Revista de Historia de la Medicina y de la Ciencia, XLIX, Madrid, 1997, 95-29.

Armus, Diego, «La enfermedad en la historiografía de América Latina moderna», Asclepio. Revista de Historia de la Medicina y de la Ciencia, 54, 2, Madrid, 2002, 41-60.

Armus, Diego, La ciudad Impura, Editorial Edhasa, Buenos Aires, 2007.

Armus, Diego, «Medicina casera, remedios y curanderos en los inicios de la medicalización de la ciudad moderna. Buenos Aires, 1870-1940», Tempos Históricos, 20, Paraná, 2016, 47-80.

Bohoslavsky, Ernesto y Di Liscia, María Silvia, «La profilaxis del viento. Instituciones represivas y sanitarias en la Patagonia argentina, 1880-1940», Asclepio. Revista de Historia de la Medicina y de la Ciencia, LX, 2, Madrid, 2008, 187-206.

Bohoslavsky, Ernesto y Godoy Orellana, Milton (eds.), Construcción estatal, orden oligárquico y respuestas sociales. Argentina y Chile 1840-1930, Buenos Aires, UNGS, Universidad Academia de Humanismo Cristiano, Prometeo Libros, 2010.

Bohoslavsky, Ernesto y Soprano, Germán (eds.), Un Estado con rostro humano. Funcionarios e instituciones estatales en Argentina (desde 1880 a la actualidad), Buenos Aires, Universidad Nacional de General Sarmiento, Prometeo Libros, 2010.

Bonaudo, Marta (dir.), Liberalismo, Estado y orden burgués (1852-1880), Tomo IV de la Colección Nueva Historia Argentina, Buenos Aires, Sudamericana, 2007 [1999].

Bubello, Juan Pablo, Historia del esoterismo en la Argentina. Prácticas, representaciones y persecuciones de curanderos, espiritistas, astrólogos y otros esoteristas, Buenos Aires, Biblos, 2010.

Carbonetti, Adrián, «La Construcción del poder médico en el marco de la formación del Estado Nacional y la reestructuración de los Estados Provinciales. 
El caso de Córdoba. 1869-1914», Terceras Jornadas de Historia de Córdoba, Córdoba, Junta Provincial de Historia, 1997, 241-257.

Carbonetti, Adrián; Aizenberg, Lilia y Rodríguez, María Laura, «La Historia Social de la Salud y la Enfermedad: conformación, logros y desafíos», Revista Estudios, 30, Córdoba, 2014, 145-157.

Castel, Robert, La metamorfosis de la cuestión social. Una crónica del salariado, Buenos Aires, Paidós, 1997 [1977].

Dahhur, Astrid, «Ataques a curanderos. La medicina y su lucha por el control social de la población en los primeros años del siglo XX», XIV Jornadas Interescuelas/Departamentos de Historia, Universidad Nacional de Cuyo, Mendoza, 2013, https://www.aacademica.org/000-010/530.

Di Liscia, María Silvia, Saberes, Terapias y Prácticas Médicas en Argentina (17501910), Madrid, Consejo Superior de Investigaciones Científicas, 2003.

Di Liscia, María Silvia, «Reflexiones sobre la nueva historia social de la salud y la enfermedad en Argentina», en Carbonetti, Adrián y González Leandri, Ricardo (eds.), Historias de salud y enfermedad en América Latina, Siglos XIX y XX, Córdoba, Editorial CEA, CONICET, 2008, 15-47.

Faberman, Judith, Las Salamancas de Lorenza. Magia, Hechicería y curanderismo en el Tucumán colonial, Buenos Aires, Siglo XXI, 2005.

Fernández, Sandra R. (comp.), Más allá del territorio. La historia regional y local como problema. Discusiones, balances y proyecciones, Rosario, Prohistoria, 2007.

Fernández, Sandra R., «El revés de la trama: contexto y problemas de la historia regional y local», en Bandieri, Susana; Blanco, Graciela y Blanco, Mónica (coords.), Las escalas de la historia comparada. Tomo 2: Empresas y empresarios. La cuestión regional, Buenos Aires, Miño y Dávila, 2008, 233-246.

Fernández, Sandra y Dalla Corte, Gabriela, Lugares para la historia: espacio, historia regional e historia local en los estudios contemporáneos, Rosario, UNR Editora, 2001.

Ferreira, Luiz Otávio, «Medicina impopular. Ciencia médica e medicina popular nas páginas dos periódicos científicos (1830-1840)», en Chaloub, Sydney et al. (orgs.), Artes e ofícios de curar no Brasil. Capítulos de História Social, Campinas, Editora Unicamp, 2003, 101-122.

Fleitas, Mirta, «iQueremos a Mano Santa!: actores y significados de una revuelta popular acontecida en 1929 en San Salvador de Jujuy», Salud Colectiva, vol. 3, 3, Remedios de Escalada, 2007, 301-313.

Gallo, Ezequiel, La pampa gringa. La colonización agrícola en Santa Fe (18701895), Buenos Aires, Edhasa, 2004 [1983].

Garcilazo, Romina, «Recurrir a las autoridades por una justa causa. El derecho de petición en la ciudad de Rosario (Argentina) 1883, 1884-1890», Temas Americanistas, 33, Sevilla, 2014, 130-152.

González Leandri, Ricardo, Curar, persuadir, gobernar. La construcción histórica de la profesión médica en Buenos Aires, 1852-1886, Madrid, CSIC, 1999. 
González Leandri, Ricardo, «El Consejo Nacional de Higiene y la consolidación de una elite profesional al servicio del Estado. Argentina, 1880-1900», Anuario de Estudios Americanos, 61,2, Sevilla, 2004, 571-593.

González Leandri, Ricardo, «La consolidación de una inteligentzia médico profesional en Argentina: 1880-1900», Diálogos. Revista Electrónica de Historia, 7, 1, Costa Rica, 2006, 36-78.

González Leandri, Ricardo, «Itinerarios de la profesión médica y sus saberes de Estado. Buenos Aires, 1850-1910», en Plotkin, Mariano y Zimmermann, Eduardo (comps.), Los saberes del Estado, Buenos Aires, Edhasa, 2012, 125-152.

Hourcade, Eduardo y Godoy, Cristina, «La economía santafesina en la segunda mitad del siglo XIX», en Ascolani, Adrián (comp.), Historia del sur santafesino. La sociedad transformada (1850-1930), Rosario, Ediciones Platino, 1993, 19-40.

Molina Jiménez, Iván y Palmer, Steven, La voluntad radiante. Cultura impresa, magia y medicina en Costa Rica (1897-1932), San José, Editorial Porvenir y Plumsock Mesoamerican Studies, 1996.

Palmer, Steven, «La "voluntad radiante" del Profesor Carbell. Medicina popular y populismo médico en Costa Rica en el decenio de 1930», en Armus, Diego (ed.), Entre médicos y curanderos. Cultura, historia y enfermedad en la América latina moderna, Buenos Aires, Grupo Editorial Norma, 2002, 259-292.

Pascual, Cecilia M., «La epidemia de cólera como condensador de sentidos. Culturas urbanas, narraciones clínicas y políticas higiénicas en Rosario, Argentina, 1886-1887», História Ciências, Saúde-Manguinhos, 24, 2, Río de Janeiro, 2017, 295-311.

Plotkin, Mariano y Zimmermann, Eduardo (comps.), Los saberes del Estado, Buenos Aires, Edhasa, 2012.

Podgorny, Irina, Charlatanes. Crónicas de remedios incurables, Buenos Aires, Eterna Cadencia, 2012.

Podgorny, Irina, Charlatanería y cultura científica en el siglo XIX, Madrid, Libros de la Catarata, 2015.

Prieto Agustina, «Rosario. Epidemias, Higiene e higienistas en la segunda mitad del siglo XIX», en Lobato, Mirta (ed.), Política, médicos y enfermedades. Lecturas de la historia de la salud en la Argentina, Mar del Plata, Biblos, 1996, 57-71.

Reguera, Andrea (coord.), Los rostros de la modernidad. Vías de transición al capitalismo. Europa y América siglos XIX y XX, Rosario, Prohistoria, 2009.

Revel, Jacques, Un momento historiográfico. Trece ensayos de historia social, Buenos Aires, Manantial, 2005.

Rivero, María Dolores; Carbonetti, Adrián y Rodríguez, María Laura, «Alternativas al saber diplomado en la escena pública: una aproximación al curanderismo a partir de la prensa escrita de las ciudades de Córdoba y de Buenos Aires, Argentina en la década de 1920», Historia y Sociedad, 33, Medellín, 2017, 19-43. 
Rodríguez, María Laura; Carbonetti, Adrián y Andreatta, María Marta, «Prácticas empíricas y medicina académica en Argentina. Aproximaciones para un análisis cuanticualitativo del Primer Censo Nacional (1869)», Historia Crítica, 49, Bogotá, 2013, 81-108.

Sedrán, Paula; Carbonetti, Adrián y Allevi, José Ignacio, «Juan P. Quinteros, espiritista. Disputas por los sentidos legítimos del arte de curar. Santa Fe, fines del siglo XIX», Revista de Indias, Madrid, en prensa.

Sowell, David, «Andanzas de un curandero en Colombia: Miguel Perdomo Neira y "la lucha entre el buen sentido y la ignorancia ciega"», en Armus, Diego (ed.), Entre médicos y curanderos, Buenos Aires, Grupo Editorial Norma, 2002, 71-103.

Suriano, Juan (comp.), La cuestión social en Argentina. 1870-1943, Buenos Aires, Ed. La Colmena, 2000. 